\title{
Review Article \\ Drug Delivery Innovations for Enhancing the Anticancer Potential of Vitamin E Isoforms and Their Derivatives
}

\author{
Christiana M. Neophytou and Andreas I. Constantinou \\ Department of Biological Sciences, Faculty of Pure and Applied Sciences, University of Cyprus, 1678 Nicosia, Cyprus
}

Correspondence should be addressed to Andreas I. Constantinou; andreasc@ucy.ac.cy

Received 20 February 2015; Revised 12 April 2015; Accepted 15 April 2015

Academic Editor: Rohit S. Mulik

Copyright (C) 2015 C. M. Neophytou and A. I. Constantinou. This is an open access article distributed under the Creative Commons Attribution License, which permits unrestricted use, distribution, and reproduction in any medium, provided the original work is properly cited.

\begin{abstract}
Vitamin E isoforms have been extensively studied for their anticancer properties. Novel drug delivery systems (DDS) that include liposomes, nanoparticles, and micelles are actively being developed to improve Vitamin E delivery. Furthermore, several drug delivery systems that incorporate Vitamin E isoforms have been synthesized in order to increase the bioavailability of chemotherapeutic agents or to provide a synergistic effect. D-alpha-tocopheryl polyethylene glycol succinate (Vitamin E TPGS or TPGS) is a synthetic derivative of natural alpha-tocopherol which is gaining increasing interest in the development of drug delivery systems and has also shown promising anticancer effect as a single agent. This review provides a summary of the properties and anticancer effects of the most potent Vitamin E isoforms and an overview of the various formulations developed to improve their efficacy, with an emphasis on the use of TPGS in drug delivery approaches.
\end{abstract}

\section{Introduction}

Vitamin $\mathrm{E}$ exists in nature in 8 natural isoforms that have exhibited diverse therapeutic properties in numerous studies over the last decades. In vitro, in vivo, and clinical studies of the Vitamin E isoforms have highlighted their antioxidant, anti-inflammatory, neuroprotective, and antithrombotic abilities among others [1-3]. Importantly, Vitamin E natural isoforms have been shown to act in a preventive and therapeutic manner against several types of cancer and are still being widely investigated for their potential efficacy in this disease [4].

Even though in vitro studies have highlighted the great anticancer potential of Vitamin E isoforms, their anticancer efficacy in animal models is hindered due to low compound bioavailability and solubility. The in vivo absorption of Vitamin $\mathrm{E}$ isoforms is limited due to their lipophilic nature and insolubility in aqueous solvents $[5,6]$. Their formulations in ethanol, DMSO, or vegetable oil emulsions limit their applications in the clinical setting. Furthermore, when Vitamin E isoforms are present in high concentration in the intestine, their absorption is reduced because their transport becomes saturated $[7,8]$. As described in detail below, Vitamin E isoforms also display nonspecific distribution in tissues and when administered at high concentrations they are rapidly metabolized and excreted in urine.

Versatile novel drug delivery systems (DDS) are actively being developed to improve Vitamin E biodistribution, pharmacokinetics, and stability and subsequently raise their levels at the target site and diminish negative side effects. These systems are based mainly on three distinctive but related approaches: liposomal formulations, nanoparticles, and micellar formulations (Figure 1). Liposomes are artificially prepared self-assembled spherical vesicles composed of one or several amphiphilic phospholipid bilayers that contain an aqueous core domain. Their size ranges from $50 \mathrm{~nm}$ to several micrometers and can entrap both hydrophilic and hydrophobic drugs isolating them from the surrounding environment. Nanoparticles $(1-100 \mathrm{nM})$ either incorporate a drug in their matrix through uniform dispersion (nanospheres) or encapsulate a drug in a cavity surrounded by a polymer membrane (nanocapsules). Polymeric micelles are comprised of a hydrophobic core, where poorly watersoluble drugs can be solubilized, and a hydrophilic shell. Their size ranges from 20 to $100 \mathrm{~nm}$. Furthermore, solubilizers, such as polyethylene glycols (PEG), are also being tested as suitable 


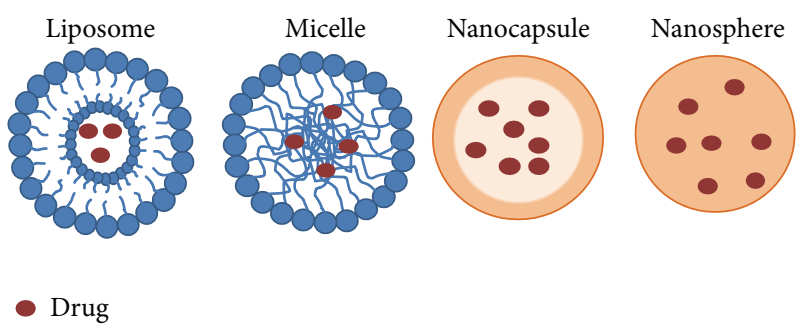

FIGURE 1: Schematic structure of liposomes, micelles, nanocapsules, and nanospheres. Liposomes are composed of one or more lipid bilayer structures surrounding an aqueous core where the drug is encapsulated. Micelles contain a hydrophilic shell and a hydrophobic core for carrying lipophilic drugs. Nanocapsules encapsulate a drug in an inner space surrounded by a polymer membrane while nanospheres are solid polymers that incorporate a drug in their matrix through uniform dispersion. Modified from [131].

formulations for human application. Besides increasing drug bioavailability, novel drug delivery systems aim to provide a synergistic effect by formulating natural Vitamin E isoforms or synthetic derivatives with other chemotherapeutic agents. This review compares and contrasts the properties and anticancer effects of the most potent Vitamin E isoforms and derivatives with emphasis on the most promising delivery approaches being developed to improve their efficacy.

\section{Vitamin E}

2.1. Structure and Metabolism. Vitamin E exists in nature as a group of 8 isoforms: $\alpha$-, $\beta$-, $\gamma$-, and $\delta$-tocopherols ( $\alpha$-TOC, $\beta$-TOC, $\gamma$-TOC, and $\delta$-TOC, resp.) and $\alpha-, \beta-, \gamma$-, and $\delta$ tocotrienols ( $\alpha$-TT, $\beta$-TT, $\gamma$-TT, and $\delta$-TT, resp.) (reviewed by [4]). Natural primary sources of tocopherols include nuts and vegetable oils, whereas tocotrienols are commonly found in palm oil, rye, oat, barley, wheat germ, and rice bran [9]. $\alpha$ TOC is the most abundant form of Vitamin $\mathrm{E}$ in nature and in vitamin supplements.

Vitamin E natural isoforms are comprised of a chroman head containing 1 phenolic acid and 1 heterocyclic ring and a phytyl tail (Figure 2). Tocopherols and tocotrienols differ in their structure: the phytyl tail of tocopherols is saturated whereas in tocotrienols it is unsaturated; the two groups also have a different number of methyl groups on the chroman head [9]. Vitamin E natural isoforms have three main moieties with distinct biological functions. (1) The first is the functional domain, composed of the redox-active hydroxyl group present in all tocopherols and tocotrienols; this is responsible for their antioxidant activity and can be modified to produce tocopheryl or tocotrienol derivatives. For example, $\alpha$-tocopherol is esterified with a succinyl moiety to produce $\alpha$-tocopheryl succinate ( $\alpha$-TOS) [10]. The functional domain is also thought to be responsible for the apoptotic properties of Vitamin E derivatives. (2) The second is the signaling domain, comprised of the aromatic rings, which regulates signaling pathways, including the protein phosphate 2/protein kinase C pathway, and (3) the hydrophobic domain, which is responsible for the binding of Vitamin E isoforms in circulating lipoproteins and biological membranes. Furthermore, the structure of the aliphatic chain may play a role in the apoptotic properties of Vitamin E isoforms, modifying membrane docking and lipid solubility [11].

Consumption of tocopherols leads to their uptake by the intestine and secretion in the circulation in chylomicron particles together with triacylglycerol and cholesterol. Chylomicron-bound Vitamin E is catabolized by lipoprotein lipase and can then be transported to peripheral tissues such as muscle, adipose, and brain [12]. The resulting chylomicron remnants are then transferred to the liver, where $\alpha$-tocopherol transfer protein ( $\alpha$-TTP) reincorporates $\alpha$-tocopherol into nascent very low-density lipoproteins (VLDLs). This enables further distribution of $\alpha$-tocopherol throughout the body [13]. When the daily intake of $\alpha$ tocopherol is excessive (over $150 \mathrm{mg}$ ), it is degraded to the hydrophilic $\alpha$-CEHC (carboxyethyl-hydroxychromans, $\mathrm{CEHC}$ ) form by a process that involves cytochrome P450 and is then primarily excreted into urine [14].

Administration of $\alpha$-TOC and tocotrienols to healthy individuals followed by detection of their levels in plasma up to $24 \mathrm{~h}$ revealed that tocotrienols are bound to the triacylglycerol particles (TRPs), low-density lipoproteins (LDLs), and high-density lipoproteins (HDLs) [15]. However, the concentration of tocotrienols in the plasma was significantly lower than that of $\alpha$-TOC. $\alpha$-TOC was also found to be bound to HDLs and LDLs in the plasma; animals studies also suggest that $\alpha$-TOC is more easily absorbed compared to the other natural isoforms $[6,16,17]$. The difference in the absorption of these compounds may be attributed to the number of methyl groups present on their chroman head which affects their lipophilicity and their transport through biological membranes.

It has been reported that oral administration of $\alpha$-TOC and $\alpha$-TT in mice led to detectable levels of both isoforms in the skin, heart, lungs, brain, liver, bone marrow, and blood suggesting that they can be effectively transported to various organs in vivo and that they display nonspecific distribution to tissues [18]. The cellular uptake of Vitamin E has been extensively investigated in the liver which is the major regulator of the levels of Vitamin E in the body. Evidence suggests that tocopherol can "flip-flop" out of the membranes due to its lipophilic nature $[19,20]$. However, regulated transport of Vitamin E in the cell may also be facilitated by lipid transfer proteins and scavenger receptor class B type I (SRBI) receptors (reviewed in [21]). As previously mentioned, Vitamin E isoforms are bound in the plasma to LDLs. The LDLR pathway is known to play a role in the cellular uptake of tocopherol from LDL but is not essential for the maintenance of normal tissue Vitamin E levels [22, 23]. HDL is also a major carrier of tocopherol in the plasma and contributes to its regulated cellular uptake possibly via the cubilin/megalin receptor system [24]. It has also been reported that SR-BImediated selective lipid uptake plays a pivotal role in the delivery of HDL-tocopherol to the central nervous system and in type II pneumocytes $[25,26]$. The exact role of SR-BI in tocopherol transport in humans is still under investigation; however, SR-BI knock-out in mice hinders the transport of Vitamin E in the ovaries, testes, lung, and brain tissues [27]; 


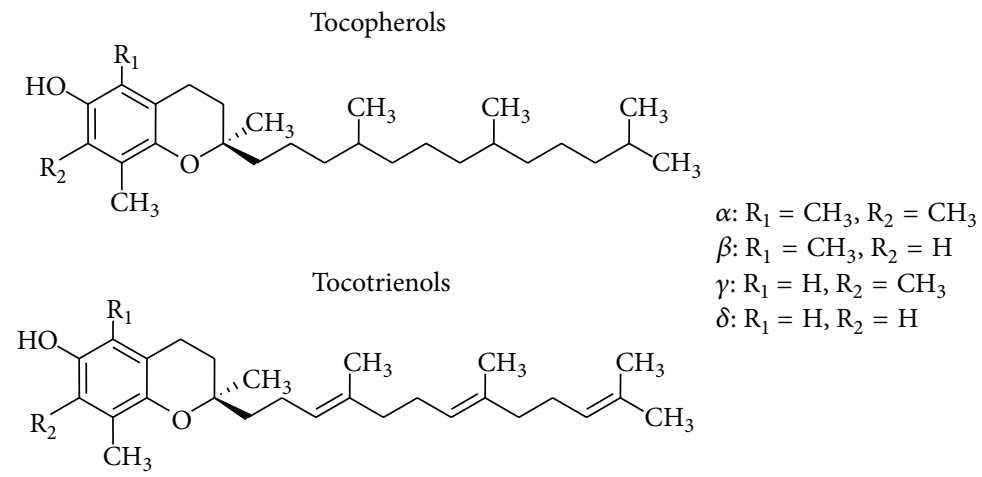

FIGURE 2: Structure of the natural isoforms of Vitamin E.

interestingly, the expression of SR-BI is affected by Vitamin E status in rat liver and HepG2 cells [28].

The intracellular transport of Vitamin $\mathrm{E}$ has also been investigated in the liver. Following internalization in hepatocytes, Vitamin E reaches the lysosomal vesicles through the endocytic pathway. TTP facilitates intracellular transport of Vitamin $\mathrm{E}$ between membrane vesicles in vitro [29]. It has been suggested that TPP, which contains a putative lysosomal targeting motif, transiently associates with the membrane vesicle by utilizing accessory proteins to anchor to the membrane and obtains Vitamin E from the endocytic vesicles [30-33]. Functional lysosomal proteins NPC1 and NPC2 are also required for the release of tocopherol from the endosomes/lysosomes [34, 35]. At the subcellular level, Vitamin E localizes at the golgi apparatus, endoplasmic reticulum, mitochondria, and lysosomes [36].

2.2. Biological Properties and Anticancer Activity. Vitamin E natural isoforms display great structural homology and have similar functions such as antioxidant activity. However, studies suggest that Vitamin E isoforms also have distinct biological activities that are not common between them. For example, $\alpha$-TOC (1) can inhibit the function of PKC, 5-lipooxygenase, and phospholipase in a posttranslational level and can activate phosphatase $2 \mathrm{~A}$ and (2) can inhibit cellular proliferation, platelet aggregation, and the monocyte attachment [37]. The above functions of Vitamin E suggest that, in addition to their antioxidant properties, these isoforms can interact with enzymes, structural proteins, lipids, and transcription factors. $\gamma$-TOC has also been found to possess anti-inflammatory and antineoplastic activities [38].

Vitamin E natural isoforms and synthetic derivatives (VitE-ISDs) have been intensively investigated for their anticancer properties against several types of cancer including breast, prostate, lung, colon, gastric, and ovarian cancers and have been found to affect survival and proliferation pathways both in vitro and in vivo (reviewed by [4]). The initial evidence regarding the anticancer potential of Vitamin $\mathrm{E}$ was derived from studies showing that people with a diet rich in Vitamin E natural isoforms have a lower risk of colon cancer $[39,40]$. Further support for the potential use of Vitamin E in cancer chemoprevention or therapy came from studies showing that dietary treatment with Vitamin E led to a reduction in the incidence of prostate cancer or a delay in its progression
[41-43]. Based on the literature, $\gamma$-TOC and $\delta$-TOC are more potent inducers of apoptosis compared to $\beta$ - and $\alpha$ tocopherols. Even though $\alpha$-TOC is a potent antioxidant, accumulating evidence in the literature suggests that $\alpha$-TOC cannot induce apoptosis [44]. Furthermore, tocotrienols are more effective proapoptotic agents than tocopherols; $\gamma$-TT and $\delta$-TT are more potent than $\alpha$ - and $\beta$-forms.

The major apoptotic pathways affected by the most potent natural and synthetic Vitamin $\mathrm{E}$ isoforms have been extensively described in other reviews $[2,4,45] . \gamma$-TT is a wellstudied natural Vitamin $\mathrm{E}$ isoform known to induce apoptosis via the extrinsic and intrinsic pathway, by inhibiting the NF$\kappa \mathrm{B}$ transcription factor and the AKT pathway thereby lowering the levels of antiapoptotic proteins such as c-FLIP, Bcl-2, $\mathrm{Bcl}-\mathrm{xL}$, and IAPs and allowing the activation of caspases 9 and $3[46,47] . \gamma$-TT also acts via the intrinsic pathway by inducing the translocation of Bax to the mitochondria and MOMP [48]. Vitamin E compounds have been found to induce both caspase-dependent and -independent pathways of apoptosis; however, the precise mechanism of CI-PCD induced by these compounds is still under investigation.

Research in the past few years has focused on structural variations within the functional moiety of natural Vitamin $\mathrm{E}$ isoforms with the aim of improving the proapoptotic potency of these agents and improving their bioavailability. Synthetic derivatives of $\alpha$-TOC (Figure 3), such as $\alpha$-tocopherol succinate ( $\alpha$-TOS) and $\alpha$-tocopheryl ether-linked acetic acid ( $\alpha$-TEA), have shown enhanced proapoptotic potency and anticancer action in tumorigenic cell lines and animal models [49-53]. Derivative $\alpha$-TOS is a potent apoptotic compound that acts as a mitocan; it exerts anticancer activity and selectively induces apoptosis in tumor cells mainly by targeting and destabilizing mitochondria (reviewed in [54]). $\alpha$-TOS generates ROS, which is known to trigger the mitochondrial pathway of apoptosis, and also inactivates Bcl-2 and Bax and induces the translocation of Bax to the mitochondria [55]. $\alpha$-TEA has been found to cooperate with chemotherapeutic agents to induce apoptosis of P53 mutant, triple negative human breast cancer cells via activating P73 suggesting that this synthetic derivative may be useful in the treatment of multidrug resistant cancers [50]. Furthermore, $\alpha$-TEA suppressed constitutively active basal levels of p-AKT, pERK, p-mTOR, and their downstream targets as well as 


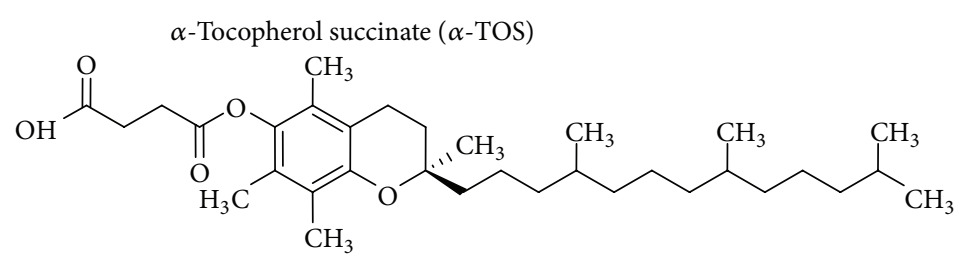

$\alpha$-tocopheryl ether-linked acetic acid ( $\alpha$-TEA)

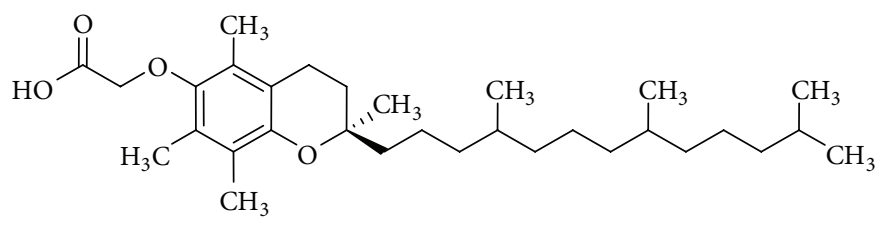

FIGURE 3: Structure of Vitamin E synthetic derivatives.

induced apoptosis in breast cancer cells [51]. $\alpha$-TEA was also found to stimulate tumor autophagy and enhance antigen cross-presentation in murine mammary and lung cancer cells [49] and induce apoptosis via ER stress by enhancing DR5/caspase-8 proapoptotic signaling in breast cancer cells [56]. Therefore, there is great interest for further evaluation of different alpha-tocopherol synthetic derivatives in in vitro and in vivo systems either as single agents or in combination with other drugs.

\section{Improving the Efficacy of Vitamin $\mathbf{E}$ Compounds with Novel Delivery Systems}

The potential of Vitamin E isoforms in cancer prevention and therapy and the problems regarding their solubility and absorption have prompted the development of novel delivery systems to intensify their effects. In addition to enhancing their own anticancer effects, several drug delivery systems that incorporate Vitamin E isoforms are being developed in order to improve the efficacy of other agents, either by increasing their bioavailability or by acting in a synergistic manner. We will review below these systems that include novel formulations for both tocopherols and tocotrienols. We will present the most important preclinical studies and their applications in cancer therapeutics.

3.1. Tocopherol Delivery Systems. As previously described, $\alpha$ tocopherol is esterified with a succinyl moiety to produce $\alpha$ tocopheryl succinate or $\alpha$-TOS. The proapoptotic properties of $\alpha$-TOS are well known and there are numerous studies showing its enhanced anticancer potency in many cancer types including melanoma, breast, prostate, gastric, mesothelioma, and colorectal (reviewed in [4]). In addition, several formulations of $\alpha$-TOS have been tested in order to improve its distribution and efficacy at the target site. Like other Vitamin $\mathrm{E}$ isoforms, $\alpha$-TOS is subjected to intestinal hydrolysis; in order to counter this effect and to increase its uptake by rapidly divided tumor cells, high-density lipoprotein(HDL)- associated $\alpha$-TOS was synthesized. Tumor cells have an excessive need for cholesterol and selectively uptake HDLassociated compounds $[57,58] . \alpha$-TOS in association with HDL was successfully delivered to A549 lung cancer cells in vitro and LL2 mouse lung carcinoma cells in vivo via SR$\mathrm{BI}$, the prime receptor mediating selective lipid uptake from HDL, and inhibited tumor cell growth [59].

It has also been reported that analogues of Vitamin $\mathrm{E}$ act as mitocans; they induce apoptosis in tumor cells by affecting mitochondria stability (reviewed in [60]). To enhance this effect, a mitochondrially targeted $\alpha$-TOS was synthesized by tagging the hydrophobic chain of the parental compound with a triphenylphosphonium group (TPP+) [61]. MitoVES was 10- to 30-fold more effective than its untagged counterpart. TPP+ has been shown to promote the selective mitochondrial uptake of antioxidant compounds driven by the mitochondrial membrane potential [62]. Conjugation of $\alpha$-TOS with TPP+ (MitoVES) potentiated its apoptotic effect in a mitochondria-depended mechanism involving the generation of ROS and upregulation of the Noxa protein in various malignant cell lines; its effect was also potentiated in two animal cancer models (Table 1) [61]. In a different study, MitoVES induced apoptosis in mesothelioma cells more efficiently than $\alpha$-TOS by destabilizing the mitochondrial membrane potential and generating ROS. The mitochondrially targeted $\alpha$-TOS also suppressed mesothelioma growth in nude mice with high efficacy [63]. MitoVES selectively suppressed the proliferation of cancer cells at subapoptotic doses by affecting mitochondrial DNA (mtDNA) transcripts. Specifically, MitoVES strongly suppressed the level of the displacement loop transcript and of mtDNA genes coding for subunits of mitochondrial complexes causing disruption of mitochondrial function. In addition, MitoVES decreased the expression of mitochondrial transcription factor A (TFAM) and diminished mitochondrial biogenesis. Importantly, the inhibition of mitochondrial transcription was replicated in vivo; MitoVES lowered the level of mtDNA transcripts in HER2 overexpressing breast cancer cells but not in normal tissue [64]. 
TABLE 1: Novel formulations to improve the delivery and anticancer effect of tocopherols alone and in combination with other drugs.

\begin{tabular}{lllll}
\hline Formulation & Cancer model & Effect & IC $_{50}$ & Reference \\
\hline \multirow{2}{*}{$\alpha$-TOS-HDL } & A549 lung cancer cells in vitro, & $\begin{array}{l}\text { High capacity of } \alpha \text {-TOS } \\
\text { uptake via the SR-BI receptor, }\end{array}$ & $\begin{array}{l}7 \mu \mathrm{g} \alpha \text {-TOS/25 } \mu \mathrm{g} \\
\text { HDL-protein/mL medium } \\
\text { inhibition of growth }\end{array}$ & LL2 mouse lung cancer in vivo
\end{tabular}

T-cell lymphoma, mesothelioma, breast, colorectal, lung, and cervical cancer, neuroblastoma,

$\alpha$-TOS-TPP+

(MitoVES) $\mathrm{FVB} / \mathrm{N}$ c-neu mice carrying the rat HER-2/neu proto-oncogene, and Balb c mice injected with colorectal HCT116 cells

\begin{tabular}{ll}
\hline -TOS-TPP+ & $\begin{array}{l}\text { Mesothelioma cells in vitro } \\
\text { and in vivo }\end{array}$
\end{tabular}
and in vivo B16-F1 mouse melanoma cells in vitro and in vivo
Robust apoptosis due to mitochondrial targeting of $\alpha$-TOS and production of ROS, suppression of tumors
MitoVES IC $_{50}$ ranging from

0.48 to $21 \mu \mathrm{M}$ depending on the cell line

Mitochondrial destabilization, loss of mitochondrial membrane potential, generation of ROS, destabilization of respiratory supercomplexes, and 0.25 to $2 \mu \mathrm{M}$ depending on the suppression of mesothelioma growth in nude mice

Homogenous cellular uptake, enhanced cytosolic delivery and effective intratumoral distribution, induction of apoptosis in vitro, and suppression of tumor growth

\begin{tabular}{|c|c|c|c|c|}
\hline $\begin{array}{l}\text { Liposomal } \\
\text { formulation of } \\
\alpha \text {-TAM }\end{array}$ & $\begin{array}{l}\text { MCF-7 or B16F10 cells } \\
\text { implanted in the peritoneum } \\
\text { of Balb/c mice, transgenic } \\
\text { FVB/N c-neu mice bearing } \\
\text { spontaneous breast } \\
\text { carcinomas }\end{array}$ & $\begin{array}{l}\text { Inhibition of proliferation of } \\
\text { cancer cells in vivo and } \\
\text { suppression of breast } \\
\text { carcinomas }\end{array}$ & $\begin{array}{l}13.3 \text { and } 5.2 \mu \mathrm{M} \text { for MCF- } 4 \\
\text { and B16F10 cells, respectively }\end{array}$ & [69] \\
\hline $\begin{array}{l}\text { Liposomal } \\
\text { formulation of } \\
\alpha \text {-TEA and 9-NC } \\
\end{array}$ & $\begin{array}{l}\text { Mouse mammary gland cell } \\
\text { line } 66 \mathrm{cl}-4 \text {-GFP in Balb/c } \\
\text { mice }\end{array}$ & $\begin{array}{l}\text { Inhibition of tumor growth } \\
\text { and metastasis }\end{array}$ & N/A & [70] \\
\hline $\begin{array}{l}\text { Micelle system of } \\
\alpha \text {-TOS-CS-PTX }\end{array}$ & $\begin{array}{l}\text { MCF-7 cells in vitro, U14 } \\
\text { cervical cancer cells in } \\
\text { Kunming mice }\end{array}$ & $\begin{array}{l}\text { Cytotoxicity in vitro, } \\
\text { inhibition of tumor growth }\end{array}$ & N/A & [74] \\
\hline $\begin{array}{l}\text { Micelle system of } \\
\alpha \text {-TOS-CS-PTX }\end{array}$ & $\begin{array}{l}\text { Human ovarian cancer cells in } \\
\text { vitro }\end{array}$ & $\begin{array}{l}\text { Improved micelle stability and } \\
\text { PTX release, increased } \\
\text { cytotoxicity }\end{array}$ & $\begin{array}{l}110 \text { and } 188 \mathrm{ng} / \mathrm{mL} \\
\text { PTX-loaded micelles modified } \\
\text { and unmodified with } \alpha \text {-TOS, } \\
\text { respectively }\end{array}$ & [75] \\
\hline $\begin{array}{l}\text { Nanoparticle } \\
\text { ssPalmE loaded } \\
\text { with VEGFR }\end{array}$ & $\begin{array}{l}\text { Renal cell carcinoma } \\
\text { (OS-RC-2-bearing mice) }\end{array}$ & $\begin{array}{l}\text { Successful delivery of VEGFR } \\
\text { and significant suppression of } \\
\text { tumor growth }\end{array}$ & N/A & [77] \\
\hline
\end{tabular}

Due to its amphipathic structure, $\alpha$-TOS forms vesicles in aqueous solutions (TS-NVs) and may be used as a prospective tool for the encapsulation and delivery of other drugs. However, $\alpha$-TOS vesicles are unstable in the presence of divalent cations, acidic $\mathrm{pH}$, and serum. In order to improve their stability, a novel nanovesicle consisting of TS and egg phosphatidylcholine (TS-EPC-NVs) was synthesized. TSEPC-NVs, at a concentration ranging from 12.5 to $50 \mu \mathrm{M}$, displayed greater stability and more potent in vivo and in vitro anticancer effects (the in vitro anticancer efficiency increased sevenfold) than that of TS-NVs that were attributed to a more effective intratumoral distribution, homogenous cellular uptake, and enhanced cytosolic delivery [65]. The TSEPC-NVs showed enhanced anticancer effects without the encapsulation of a drug, highlighting the potential usefulness of Vitamin $\mathrm{E}$ in cancer. 
Vitamin E analogues can be easily incorporated into lipid bilayers to produce liposomes of various surface modifications and size distributions. Liposomes can encapsulate a single drug for monotherapy or several drugs for multitargeted effects. The drugs incorporated into liposomes are passively delivered to tumor tissue by enhanced permeation and retention (EPR) effect. The EPR effect is the property by which certain molecules accumulate in tumors rather than in normal tissues, due to the presence of more blood vessels in tumor tissue $[66,67]$. In order for tumor cells to grow quickly, they stimulate the production of blood vessels for their nutritional and oxygen supply. These newly formed tumor vessels are usually abnormal in form and architecture which leads to abnormal molecular and fluid transport dynamics, especially for macromolecular drugs. Thus, the EPR effect helps to carry micelles, nanoparticles, and liposomes and spread them inside the cancer tissue.

A derivative of $\alpha$-TOC, a-tocopheryl maleamide ( $\alpha$ TAM), contains a noncleavable amide bond and has exhibited enhanced apoptotic properties in vitro [68]. In a liposomal formulation, $\alpha$-TAM induced apoptosis in human and murine cancer cells in vitro and suppressed tumors in mouse models. Importantly, $\alpha$-TAM's nonspecific toxicity and immunotoxicity were diminished when incorporated into liposomes [69]. Another derivative of Vitamin E with potent anticancer activity, $\alpha$-TEA, in combination with 9nitrocamptothecin (9-NC), a derivative of camptothecin, was formulated into liposomes using dilauroylphosphatidylcholine and administered by aerosol in tumor-bearing mice. Liposome-formulated $\alpha$-TEA and 9-NC significantly reduced the growth, induced apoptosis, and inhibited metastasis of mouse mammary gland cell line ( $66 \mathrm{cl}-4-\mathrm{GFP})$. Treatment of $66 \mathrm{cl}-4$-GFP cells in culture for 3 days with a combination of $\alpha$-TEA $(10 \mathrm{mg} / \mathrm{mL}$, singly produces $38 \%$ apoptosis) and 9 -NC $(15.6,31.3,62.5$, or $125 \mathrm{ng} / \mathrm{mL}$; singly produces $2-7 \%$ apoptosis) produced $47 \%, 58 \%, 64 \%$, and $69 \%$ apoptosis. In control animals, the incidence of macroscopic lung metastasis was $83 \%$ compared to $8 \%$ in $\alpha$-TEA-, $9-\mathrm{NC}-$, or combinationtreated mice [70]. It was calculated that approximately $36 \mathrm{~g}$ $\alpha$-TEA and $0.4 \mathrm{~g} 9$-NC per mouse per day were deposited in the lungs, respectively.

Micelles are commonly used as a platform for the delivery of hydrophobic drugs. They display good solubilization efficiency and high stability upon dilution and their nanoscale dimensions permit the efficient accumulation in tumor tissues via the EPR effect [71-73]. Chitosan is widely used in micellar drug delivery applications due to its excellent biocompatibility, nontoxicity, biodegradability, and low immunogenicity. $\alpha$-TOS has been synthesized in combination with paclitaxel (PTX) in chitosan derivative polymeric micelles for cancer cell delivery. This conjugate self-assembled in aqueous medium to form micelles and PTX was incorporated into the micellar core for intravenous delivery. Commonly, PTX is diluted in a 50:50 mixture with Cremophor EL which has severe toxic side effects. A polymeric micelle system of $\alpha$-tocopherol succinate-amphiphilic chitosan (CS-TOS) loaded with PTX displayed comparable cytotoxicity to PTX-Cremophor EL and free PTX against MCF-7 cells in vitro and significantly inhibited the growth of U14 tumors in vivo at doses of 10 and $20 \mathrm{mg} / \mathrm{kg}$ with no toxic side effects [74]. This further highlights the usefulness of $\alpha$-tocopherol succinate in replacing harmful lipophilic solvents. In an aim of improving the therapeutic efficiency and reducing side effects of PTX, $\alpha$-TOS-grafted chitosan oligosaccharide was synthesized and physically loaded by PTX and $\alpha$-TOS. The incorporation of $\alpha$-TS into the micelles led to an increase of the hydrophobic interaction between PTX and the micelles core, thereby improving micelle stability, reducing micelle size, and facilitating PTX release from the micelles. In addition, $\alpha$-TS/PTX-loaded micelles displayed higher cytotoxicity against human ovarian cancer cells in vitro than that of PTX-loaded micelles and PTX alone [75].

$\alpha$-TOS has also been used as a hydrophobic scaffold for a novel molecular platform, the SS-cleavable Proton-Activated Lipid-like Material (ssPalm). This pDNAencapsulating nanoparticle was designed to degrade in the cytosolic environment. The lipid envelope coating the condensed DNA/polycation complex was a stable bilayer composed of the ssPalm molecule which mounts dual sensing motifs that respond to various intracellular environments and allow for the release of the encapsulated molecule in the cytoplasm [76]. ssPalm contains a proton-sponge unit (tertiary amines) that functions in response to an acidic environment, such as in an endosome or lysosome, and disulfide bonding that can be cleaved in a reducing environment such as the cytosol. ssPalmE, where Vitamin E ( $\alpha$-tocopherol succinate) was used as a hydrophobic scaffold, successfully delivered a solute form of VEGFR in vivo and showed enhanced antitumor action in mice bearing tumors established from a renal cell carcinoma (OS-RC-2). The ssPalmE formulation was significantly more effective than ssPalmM, where Myristic acid was the hydrophobic scaffold, suggesting that $\alpha$-TOS worked synergistically with the VEGFR agonist against renal cell carcinoma in vivo [77]. LNPssPalmM and LNPssPalmE were administered intravenously at a dose of $37.5 \mu \mathrm{g}$ of $\mathrm{pDNA} / \mathrm{mouse} 3$ times at every 3 days.

3.2. Tocotrienol Delivery Systems. Novel DDS aim to target compounds to tumor sides thereby diminishing side effects on healthy tissues. To achieve specific distribution to tumors, tocotrienol extract from palm oil or tocotrienol-rich fraction (TRF) was encapsulated within vesicles bearing transferrin (Table 2). The transferrin receptor is a cell membraneassociated glycoprotein involved in iron homeostasis and the regulation of cell growth; since transferrin receptors are overexpressed up to 100-fold in several types of cancer cells compared to normal cells, these vesicles could selectively localize to tumors. This novel formulation of TRF led to a 3fold higher uptake and improved its toxicity more than 100fold in A431 (epidermoid carcinoma), T98G (glioblastoma), and A2780 (ovarian carcinoma) cell lines compared to TRF solution. The vesicle formulations of TRF were all significantly more effective than the free drug by at least 80 times, with $\mathrm{IC}_{50}$ ranging from $0.05 \pm 0.02$ to $1.42 \pm 0.30 \mu \mathrm{g} / \mathrm{mL}$ depending on the cell line. Intravenous administration of transferrin-bearing vesicles loaded with TRF induced tumor regression and improvement of animal survival in a murine 
TABLE 2: Novel formulations to improve the delivery and anticancer effect of tocotrienols alone and in combination with other drugs.

\begin{tabular}{|c|c|c|c|c|}
\hline Formulation & Cancer model & Effect & $\mathrm{IC}_{50}$ & Reference \\
\hline $\begin{array}{l}\text { Unilamellar } \\
\text { TRF-vesicles } \\
\text { bearing transferrin }\end{array}$ & $\begin{array}{l}\text { A431 (epidermoid carcinoma), } \\
\text { T98G (glioblastoma), and } \\
\text { A2780 (ovarian carcinoma) } \\
\text { cells, A431 cells implanted in } \\
\text { BALB/c mice }\end{array}$ & $\begin{array}{l}\text { Threefold higher TRF uptake } \\
\text { and more than } 100 \text {-fold } \\
\text { improved cytotoxicity in vitro, } \\
\text { tumor regression, and } \\
\text { improvement of animal } \\
\text { survival }\end{array}$ & $\begin{array}{l}\text { Ranging from } 0.05 \pm 0.02 \text { to } 1.42 \\
\pm 0.30 \mu \mathrm{g} / \mathrm{mL} \text { depending on the } \\
\text { cell line }\end{array}$ & {$[78]$} \\
\hline $\begin{array}{l}\text { Multilamellar } \\
\text { TRF-vesicles } \\
\text { bearing transferrin }\end{array}$ & $\begin{array}{l}\text { A431 human epidermoid } \\
\text { carcinoma, T98G human } \\
\text { glioblastoma, B16-F10 mouse } \\
\text { melanoma cells, and A431 or } \\
\text { B16-F10-luc-G5 tumors in } \\
\text { BALB/c mice }\end{array}$ & $\begin{array}{l}\text { Improved TRF uptake and } \\
\text { cytotoxicity in vitro, slower } \\
\text { growth of A } 431 \text { and B16-F10 } \\
\text { tumors, and long-term } \\
\text { survival of } 100 \% \text { of the } \\
\text { animals }\end{array}$ & $\begin{array}{l}\text { Ranging from } 0.89 \pm 0.11 \text { to } 4.09 \\
\pm 0.65 \mu \mathrm{g} / \mathrm{mL} \text { depending on the } \\
\text { cell line }\end{array}$ & [79] \\
\hline $\begin{array}{l}\text { Lipid } \\
\text { nanoemulsions } \\
\text { loaded with TRF } \\
\text { and Simvastatin }\end{array}$ & $\begin{array}{l}\text { MCF-7 and MDA-MB-231 } \\
\text { breast cancer cells }\end{array}$ & Decrease of TRF IC $\mathrm{I}_{50}$ & $\begin{array}{l}\text { Decreased from } 14 \text { to } 10 \mu \mathrm{M} \text { in } \\
\text { MCF-7 and from } 7 \text { to } 4.8 \mu \mathrm{M} \text { in } \\
\text { MDA-MB-231 cells when } \\
\text { Simvastatin was added }\end{array}$ & {$[84]$} \\
\hline $\begin{array}{l}\text { Nanoemulsified } \\
\text { formulation of } \\
\text { T3-rich palm oil } \\
\text { (Tocomin-NE) } \\
\end{array}$ & $\begin{array}{l}\text { Human cutaneous carcinoma } \\
\text { in vitro }\end{array}$ & Increased cytotoxicity & $\begin{array}{l}\text { Tocomin-NE } 42.6 \pm 3.8 \mathrm{mM} \text { and } \\
47.3 \pm 3.2 \mathrm{mM} \text {, Tocomin control } \\
217.4 \mathrm{mM} \text { and } 278.5 \mathrm{mM} \text { in A } 431 \\
\text { cells and SCC- } 4 \text { cells, respectively }\end{array}$ & {$[85]$} \\
\hline $\begin{array}{l}\text { EPI-NPs } \\
\text { coadministered } \\
\text { with tocotrienols }\end{array}$ & $\begin{array}{l}\text { Hep G2 (HCC) cells in vitro, } \\
\text { HCC mouse model in Albino } \\
\text { mice }\end{array}$ & $\begin{array}{l}\text { Enhanced antiproliferative } \\
\text { effect in vitro, enhanced } \\
\text { apoptosis, and reduced VEGF } \\
\text { level in vivo }\end{array}$ & $\begin{array}{l}\text { Free EPI viability }>90 \% \\
\text { EPI-NPs } 0.9 \mu \mathrm{g} / \mathrm{mL}, \text { EPI-NPs } \\
\text { tocotrienols } 2 \mu \mathrm{g} / \mathrm{mL}\end{array}$ & {$[86]$} \\
\hline
\end{tabular}

Tocotrienol-rich fraction (TRF), Epirubicin (EPI), nanoparticles (NPs), and Hepatocellular carcinoma (HCC).

xenograft model and was well tolerated by animals [78]. However, tumor regression lasted only for the duration of the treatment. To improve the therapeutic efficacy, TRF was encapsulated in multilamellar rather than unilamellar transferrin-bearing vesicles. Multilamellar vesicles contain more than one phospholipid bilayers compared to unilamellar; this may improve tocotrienol loading within the lipidic membranes. This novel formulation not only significantly improved tocotrienol uptake by transferrin-expressing tumor cells but also improved the in vitro therapeutic efficacy of free tocotrienol from 17- to 72-fold depending on the cell line. Importantly, this novel TRF formulation led to complete tumor suppression for $40 \%$ of B16-F10 murine melanoma tumors and $20 \%$ of A431 human epidermoid carcinoma tumors, with long-term survival of the animals [79].

In addition to their inherent anticancer properties, tocotrienols can also potentiate the anticancer activity of other drugs thereby lowering their effective concentration and limiting toxicity. Tocotrienols can enhance the effect of several compounds including cox-2 inhibitor celecoxib, tyrosine kinase inhibitor gefitinib, and statins such as Simvastatin [80-82]. Simvastatin is a potent inhibitor of 3hydroxy-3-methylglutaryl-coenzyme A (HMGCoA) reductase that displays anticancer activity but its clinical use is limited by high-dose toxicity. In an effort to produce bioactive, injectable nanoparticles that carry both TRF and Simvastatin, parenteral lipid nanoemulsions loaded with both compounds were synthesized; nanoemulsions are comprised of nanoscale droplets in the range of $1-100 \mathrm{~nm}$ and have many applications in pharmaceutics (reviewed in [83]). Lipid nanoemulsions containing Simvastatin at subtherapeutic doses decreased the $\mathrm{IC}_{50}$ of TRF in MCF-7 (from 14 to $10 \mu \mathrm{M}$ ) and MDA-MB-231 (from 7 to $4.8 \mu \mathrm{M}$ ) breast cancer cells [84]. Different nanoemulsions for optimized incorporation of tocotrienol- (T3-) rich palm oil or Tocomin obtained with different homogenization strategies have also been tested for their anticancer activities. Adopted hybrid nanoemulsification of Tocomin (Tocomin-NE) displayed 2,2-diphenyl-1-picrylhydrazyl- (DPPH-) radical scavenging capacity which effectively permeated cell membranes by diffusion and demonstrated significantly stronger cytotoxic profiles (at least 5-fold lower $\mathrm{IC}_{50}$ values, compared to those estimated for the Tocomin-control). This hybrid nanoemulsified formulation of T3-rich palm oil may be used in topical delivery against skin carcinomas [85].

Tocotrienols have also been formulated with Epirubicin (EPI) to reduce its toxicity. EPI is an anthracycline derivative used commonly in the treatment of Hepatocellular carcinoma (HCC) but displays serious side effects including cardiomyopathy and congestive heart failure. To specifically target hepatocytes, EPI was loaded in chitosan-PLGA nanoparticles linked with asialofetuin (EPI-NPs); furthermore, to reduce cardiotoxicity, targeted EPI-NPs were coadministered with tocotrienols. Combined therapy of tocotrienols with EPINPs enhanced apoptosis, reduced VEGF level in a dose dependent manner, and provided protection against oxidative stress and inflammation induced by EPI in the heart [86]. 


\section{D-Alpha-Tocopheryl Polyethylene Glycol Succinate (TPGS)}

4.1. Physicochemical Properties. D-alpha-tocopheryl polyethylene glycol succinate (Vitamin E TPGS or TPGS) is a synthetic derivative of natural alpha-tocopherol which is gaining increasing interest in the development of drug delivery systems (reviewed by [87]). TPGS, prepared from the esterification of $\alpha$-TOS and polyethylene glycol (PEG) 1000, possesses the advantages of PEG and Vitamin E in drug delivery applications, including the ability to extend the halflife of the drug in the plasma.

The PEG 1000 has an average molecular weight of about 1000 Dalton and is synthesized from fossil fuel while alphatocopherol succinate is produced by the alpha-tocopherol which is esterified to succinic acid. TPGS has an average molecular weight of 1513 and an amphiphilic structure of lipophilic alkyl tail and hydrophilic polar head; the PEG 1000 portion of the molecule is water soluble, while the alphatocopherol portion is fat soluble [87]. Structurally, TPGS is very similar to the tocopherols; it has a phytyl tail and a chroman ring but the hydroxyl group on the chroman head is esterified to the polyethylene 1000 succinate moiety (Figure 4). The molecular formula is $\mathrm{C} 33 \mathrm{O} 5 \mathrm{H} 54\left(\mathrm{CH}_{2}\right.$ $\left.\mathrm{CH}_{2} \mathrm{O}\right) n$, where " $n$ " represents the number of polyethylene oxide moieties attached to the acid group of alpha tocopheryl succinate.

TPGS is a waxy solid that completely dissolves in water and forms its own micelles; the hydrophilic regions of the molecule are in contact with the surrounding solvent, sequestering the hydrophobic tail regions in the micelle centre. It is also miscible with oils, other surfactants, and cosolvents. TPGS has a melting point around $37-41^{\circ} \mathrm{C}$ and is heat stable at temperatures up to $199^{\circ} \mathrm{C}$ [88]. This is very important for applications in the pharmaceutical industry because it can be processed at thermally stable temperatures without degradation. TPGS is stable at $\mathrm{pH} 4.5-7.5$; however, it degrades in alkaline or highly acidic environments where the ester linkages are hydrolyzed [88].

TPGS was developed in the 1950s by Eastman Chemical Company (Kingsport, TN) as a water-soluble form of Vitamin $\mathrm{E}$ in order to be administered to individuals who cannot absorb naturally occurring lipophilic alpha-tocopherol. These include patients with cystic fibrosis, Crohn's disease, short bowel disease, pancreatic enzyme deficiency, or cholestatic liver disease [89-91]. Importantly, the United States' Food and Drug Administration (FDA) as well as the European Food Safety Authority (EFSA) has already approved TPGS as a safe pharmaceutical adjuvant used in drug formulation and has estimated the safety limits for TPGS use for research purposes [92, 93]. It has been reported that the acute oral median lethal dose $\left(\mathrm{LD}_{50}\right)$, which is defined as the quantity of an agent that will kill 50 percent of the test subjects within a designated period, is $>7 \mathrm{~g} / \mathrm{kg}$ for young adult rats of both sexes [94]. Following studies both in humans and in animals to address the bioavailability and safety of TPGS, the EFSA concluded that the overall no-observedadverse-effect level (NOAEL) of TPGS is $1000 \mathrm{mg} / \mathrm{kg}$ bw/day. In addition, TPGS was found to be nongenotoxic [95].
The mechanism of TPGS to enter the enterocyte and become absorbed has also been investigated: TPGS may be hydrolyzed to free alpha-tocopherol in the stomach by nonenzymatic hydrolysis, in the proximity of the brush border epithelium by esterase hydrolysis, and on the surface of the enterocytes via a lipase or entire TPGS micelles can pass through cell membranes thereby enabling the absorption of the intact TPGS molecule [96].

In recent years, TPGS has been intensively applied in developing various drug delivery systems as an absorption enhancer, emulsifier, solubilizer, additive, permeation enhancer, and stabilizer. The coadministration of TPGS has been shown to enhance drug solubility, to inhibit Pglycoprotein (P-gp) mediated multidrug resistance (MDR), and to increase the oral bioavailability of anticancer drugs [97-100]. As an effective emulsifier, TPGS has been shown to greatly enhance the performance of nanoparticles, resulting in much higher cellular uptake of the drug as well as more desirable in vivo pharmacokinetics [101-103]. Importantly, emerging evidence in the literature suggests that TPGS not only may be useful in cancer chemotherapy as a carrier drug but also may act synergistically or enhance the effect of anticancer drugs.

4.2. Anticancer Activity as a Single Agent. As a single agent, TPGS has been found to inhibit the growth of human prostate and lung carcinoma cells both in vitro and in vivo $[105,106]$. TPGS inhibited the growth of A549 human lung carcinoma cells in vivo and, in an in vitro cell culture, more potently than $\alpha$-TOS. Compared to $\alpha$-TOS, TPGS was more effective at inducing apoptosis in A549 cells as measured by DNA fragmentation; furthermore, at $40 \mu \mathrm{M}$ concentration, TPGS induced the production of ROS [105]. Since PEG conjugation may affect the rate of cell uptake of drugs, the time-dependent accumulation of $\alpha$-TOS and TPGS in H460 cells was measured. However, the time-dependent uptake of TPGS into cells did not differ from that of $\alpha$ TOS. Furthermore, since TPGS may be hydrolyzed after entering the cells, the intracellular concentration of TPGS was measured following treatment for up to $8 \mathrm{~h}$ and no detectable levels of $\alpha$-TOS were found [105]. This indicates that TPGS is not rapidly hydrolyzed to $\alpha$-TOS and that the enhanced antitumor efficacy of TPGS was not due to its increased uptake into cells.

The ability of TPGS to induce apoptosis was also investigated in androgen receptor negative (AR-) DU145, PC3, and androgen receptor positive $(\mathrm{AR}+) \mathrm{LNCaP}$ prostate cancer cells [106]. TPGS induced caspase-3 activity solely in the AR+ LNCaP cells; however, TPGS induced dominant caspaseindependent programmed cell death (CI-PCD) in all cell lines examined, suggesting that the molecular pathways being induced by the compound may depend on the cellular microenvironment. In a recent study conducted by our group, TPGS at $20 \mu \mathrm{M}$ induced G1/S cell cycle arrest and apoptosis in breast cancer cell lines MCF-7 and MDA-MB-231. An investigation of the molecular mechanism of action of TPGS revealed that induction of G1/S phase cell cycle arrest is associated with upregulation of P21 and P27Kip1 proteins. Induction of apoptosis by TPGS involved the inhibition of 


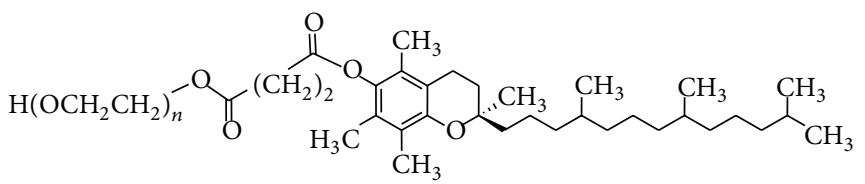

FIGURE 4: D-alpha-tocopheryl polyethylene glycol succinate structure. TPGS is synthesized from the esterification of $\alpha$-TOS and PEG 1000 . Modified from [104].

phospho-AKT and the downregulation of the antiapoptotic proteins Survivin and Bcl-2 [107]. Importantly, TPGS did not reduce the viability or proliferation of "normal" (nontumorigenic) immortalized cells (MCF-10A and MCF-12F) suggesting that its effects are cancer cell-specific.

4.3. Applications in Drug Delivery Systems. TPGS has been used in various drug delivery systems as a solubilizer/absorption enhancer, as a permeation enhancer, and as a potent P-gp inhibitor. Solubilizers/absorption enhancers are functional agents included in formulations to increase the solubility or improve the absorption of a substance. TPGS can increase the solubility of drugs such as cyclosporines, taxanes, steroids, and antibiotics by incorporation into TPGS micelles [108]. TPGS has been used as a solubilizer for PTX, celecoxib, corticosteroids, capuramycin analog SQ641, and Propofol (reviewed by [88]). Furthermore, TPGS has been shown to increase the absorption flux of HIV protease inhibitor Amprenavir and to enhance the bioavailability of cyclosporine in humans and of Colchicine in rats $[109,110]$. TPGS has also been used as a permeation enhancer; it is incorporated into formulations to promote their permeation through the skin or intestinal walls. TPGS was found to enhance the permeability of Amprenavir and Colchicine and has potential as an enhancer of drug permeability in colonic tissue $[88,111]$.

TPGS has also been used in combination with other compounds due to its ability to inhibit P-gp, an ATP-dependent drug efflux pump, also known as multidrug resistance protein 1 (MDR1) or ATP-binding cassette subfamily B member 1 (ABCB1). P-gp is responsible for the transport of a wide variety of substrates across extracellular and intracellular membranes. It is widely expressed in hepatocytes, the renal proximal tubular cells, intestinal epithelium, adrenal gland, and capillary endothelial cells comprising the blood-brain and blood-testis barrier. P-gp is often overexpressed in cancer cells and confers MDR by decreasing drug accumulation of chemotherapeutic drugs such as PTX, Etoposide, Doxorubicin (DOX), and Vinblastine. TPGS can inhibit the P-gp ATPase (P-gp energy source of active transport) by binding to the nontransport active binding site, resulting in inhibition of P-gp mediated drug transport and multidrug resistance $[99,112]$. Specifically, combination of TPGS with DOX, Vinblastine, PTX, or Colchicine was found to enhance their cytotoxicity in NIH 3T3 cells transfected with the human MDR1 cDNA [99]. In a different study, TPGS and high concentrations of polysorbate 80 inhibited in vitro both efflux transporters, ABCB1 (P-gp) and ABCC2 (MRP2), that play an essential role in the limitation of oral bioavailability of drugs [113]. So far, TPGS synthesized with PEG-1000 is the most potent efflux pump inhibitor [114]. Furthermore, TPGS can inhibit cytochrome P450 3A (CYP3A) that has been associated with deactivation of several anticancer drugs [115].

Recent studies suggest that the coadministration of TPGS with chemotherapeutic agents may overcome drug resistance by increasing their cellular entry and retention and by acting in a synergistic manner (Table 3 ). The addition of TPGS $(0.03 \%(\mathrm{w} / \mathrm{w}))$ in a nanocarrier loaded with DOX decreased P-gp activity in MCF-7/ADR cells, increased the nuclear accumulation of the drug, and increased the therapeutic efficacy against the resistant cell line [116]. Cells were treated with free Dox (from $0.13 \mu \mathrm{M}$ to $10 \mu \mathrm{M}$ ) and TPGS-coated porphyrin-polylactide nanoparticles (PPLA-NPs) or TPGScoated Dox-PPLA-NPs (from $0.07 \mu \mathrm{M}$ to $4.3 \mu \mathrm{M}$ ). When the PPLA-NPs were coated with TPGS, cell viability was significantly reduced even at the lowest concentrations [116]. In an alternative approach to overcome resistance in MCF7/ADR cells, DOX was loaded in mitochondria-targeted $\mathrm{pH}-$ responsive (PDPA) micelles containing TPGS. In the acidic $\mathrm{pH}$ of early endosomes, the DOX payload was released while the TPGS component synergistically improved the cytotoxicity of the agent by reducing the mitochondrial transmembrane potential. PDPA/TPGS micelles reduced the $\mathrm{IC}_{50}$ of DOX in MCF-7/ADR cells by a sixfold magnitude [117]. A TPGS-mixed micelle system loaded with Resveratrol has also been formulated. Resveratrol has shown efficacy in overcoming chemoresistance in breast cancer but its effects are hindered by poor absorption and rapid metabolism. Resveratrol-loaded mixed micelles composed of methoxy poly (ethylene glycol)-b-polycaprolactone (mPEG-PCL) and TPGS increased Resveratrol uptake by MCF-7/ADR cells and induced higher rates of apoptosis. Blank mixed micelles did not affect the proliferation of MCF-7/ADR cells $(<10 \%$ inhibition), whereas Resveratrol alone $(0-100 \mu \mathrm{M})$ inhibited the proliferation of MCF-7/ADR cells in a dose dependent manner. Resveratrol-loaded mixed micelles enhanced the cytotoxicity of Resveratrol against MCF-7/ADR cells at all of the tested concentrations. Furthermore, Resveratrol-loaded mixed micelles inhibited the activity of P-gp and significantly enhanced DOX cellular accumulation and cytotoxicity in MCF-7/ADR cells [118].

TPGS has also been used in several formulations in order to achieve targeted delivery of chemotherapeutic drugs and reduce negative side effects. Recently, TPGS-based copolymers were synthesized, conjugated with Herceptin for targeted delivery of anticancer drugs such as Docetaxel (DTX) to cancer cells overexpressing the HER-2 receptor. Docetaxel was used at concentrations ranging from 0.025 to 
TABLE 3: TPGS-based delivery systems of anticancer drugs.

\begin{tabular}{|c|c|c|c|c|c|}
\hline Formulation & Drug & Cancer type & Effect & $\mathrm{IC}_{50}$ & Reference \\
\hline Nanoparticle & DOX & MCF-7/ADR cells in vitro & $\begin{array}{l}\text { Decreased P-gp activity, } \\
\text { increased drug nuclear } \\
\text { accumulation, and } \\
\text { increased therapeutic } \\
\text { efficacy }\end{array}$ & N/A & {$[116]$} \\
\hline $\begin{array}{l}\text { Mitochondria- } \\
\text { targeted } \\
\text { pH-responsive } \\
\text { micelles }\end{array}$ & DOX & $\begin{array}{l}\text { MCF-7/ADR cells in vitro } \\
\text { and in vivo }\end{array}$ & $\begin{array}{l}\text { Reduced mitochondrial } \\
\text { transmembrane potential, } \\
\text { synergistic cytotoxicity }\end{array}$ & $\begin{array}{l}\text { DOX } 73.2 \mu \mathrm{g} / \mathrm{mL}, \\
\text { PDPA-TPGS-DOX } \\
16.7 \mu \mathrm{g} / \mathrm{mL}\end{array}$ & [117] \\
\hline $\begin{array}{l}\text { TPGS-mPEG-PCL } \\
\text { micelles }\end{array}$ & Resveratrol & MCF-7/ADR cells in vitro & $\begin{array}{l}\text { Increased Resveratrol } \\
\text { uptake, enhanced } \\
\text { apoptosis, and inhibition of } \\
\text { P-gp activity }\end{array}$ & N/A & {$[118]$} \\
\hline $\begin{array}{l}\text { TPGS copolymers } \\
\text { conjugated with } \\
\text { Herceptin loaded } \\
\text { with DTX }\end{array}$ & DTX & SK-BR-3 cancer cells & $\begin{array}{l}\text { Targeted delivery, efficient } \\
\text { cellular uptake, and } \\
\text { improved cytotoxicity }\end{array}$ & $\begin{array}{l}\text { Nanoparticles without } \\
\text { Herceptin } 3.29 \mu \mathrm{g} / \mathrm{mL} \text { and } \\
\text { with Herceptin } 0.341 \mu \mathrm{g} / \mathrm{mL}\end{array}$ & [119] \\
\hline $\begin{array}{l}\text { TPGS coated } \\
\text { liposomes of DTX }\end{array}$ & DTX & C6 glioma cells & $\begin{array}{l}\text { Enhanced cellular uptake } \\
\text { and cytotoxicity }\end{array}$ & $\begin{array}{l}\text { DTX alone } 37.04 \pm 1.05, \\
\text { TPGS coated liposomes } \\
5.93 \pm 0.57 \mu \mathrm{g} / \mathrm{mL}\end{array}$ & {$[120]$} \\
\hline $\begin{array}{l}\text { Transferrin- } \\
\text { conjugated TPGS } \\
\text { micelles }\end{array}$ & DTX & $\begin{array}{l}\text { MDA-MB-231 cells in vitro } \\
\text { and in xenograft SCID mice }\end{array}$ & $\begin{array}{l}\text { Targeted delivery, higher } \\
\text { cellular uptake, higher } \\
\text { cytotoxicity, and reduced } \\
\text { tumor size }\end{array}$ & $\begin{array}{l}\text { DTX alone } 13.63 \pm 0.12, \\
\text { nontargeted micelles } 0.89 \pm \\
0.10, \text { and targeted micelles } \\
0.19 \pm 0.04 \mu \mathrm{g} / \mathrm{mL}\end{array}$ & {$[121]$} \\
\hline TPGS micelle & Cisplatin & $\begin{array}{l}\text { HepG2 hepatocarcinoma } \\
\text { cells }\end{array}$ & $\begin{array}{l}\text { Enhanced cytotoxicity, } \\
\text { neuroprotective effects }\end{array}$ & $\begin{array}{l}\text { Cisplatin alone } 3.95 \mu \mathrm{g} / \mathrm{mL} \text {, } \\
\text { TPGS micelle } 1.36 \mu \mathrm{g} / \mathrm{mL}\end{array}$ & {$[122]$} \\
\hline $\begin{array}{l}\text { TPGS-emulsified } \\
\text { PLGA-mPEG } \\
\text { nanoparticles } \\
\end{array}$ & PTX & $\begin{array}{l}\text { IGROV1 ovarian cancer } \\
\text { cells in vitro and in vivo }\end{array}$ & Decreased toxicity & $\mathrm{N} / \mathrm{A}$ & {$[123]$} \\
\hline $\begin{array}{l}\text { TPGS-emulsified } \\
\text { polymeric } \\
\text { nanoparticles } \\
\text { (TENPs) }\end{array}$ & PTX & $\begin{array}{l}\text { A549 lung cancer xenograft } \\
\text { models }\end{array}$ & Inhibition of tumor growth & N/A & {$[124]$} \\
\hline $\begin{array}{l}\text { Dendrimer-TPGS } \\
\text { micelles }\end{array}$ & PTX, DTX & $\begin{array}{l}\text { MCF-7 and A549 cancer } \\
\text { cells }\end{array}$ & $\begin{array}{l}\text { Enhanced solubility and } \\
\text { increased cytotoxicity }\end{array}$ & N/A & {$[125]$} \\
\hline $\begin{array}{l}\text { TPGS-PLA } \\
\text { micelles }\end{array}$ & $\begin{array}{l}\text { Crizotinib, } \\
\text { Palbociclib, } \\
\text { and Sildenafil }\end{array}$ & A549 lung cancer cells & Improved cytotoxic effect & $\begin{array}{l}\mathrm{IC}_{50}(\mu \mathrm{M}) \text { : Crizotinib } 26.07, \\
\text { Palbociclib, } 17.65 \text {, double } \\
\text { treatment } 17.47 \text {, and triple } \\
\text { treatment } 13.23\end{array}$ & {$[126]$} \\
\hline $\begin{array}{l}\alpha \text {-TOS-TPGS-2k } \\
\text { nanoparticles }\end{array}$ & DOX & $\begin{array}{l}\text { MCF-7 cells, } \\
\text { CT26-tumor-bearing mice }\end{array}$ & $\begin{array}{l}\text { Reduced cell growth, delay } \\
\text { in tumor growth }\end{array}$ & $\begin{array}{l}\text { In vitro } \mathrm{IC}_{50}(\mu \mathrm{M}): \text { TPGS } 22 \\
\pm 2, \text { TPGS + TOS } \\
10.1 \pm 0.8 \\
\text { TPGS + TOS + DOX } \\
1.4 \pm 0.4\end{array}$ & [128] \\
\hline Nanoparticle & $\mathrm{MH}$ & A549 in vitro and in vivo & Enhanced toxicity & $\begin{array}{l}\text { In vitro } \mathrm{IC}_{50}(\mu \mathrm{M}) \text { : free } \mathrm{MH} \\
56.23, \mathrm{TPGS}-\mathrm{MH} \\
\text { nanoparticles } 28.89\end{array}$ & [129] \\
\hline
\end{tabular}

Methoxy poly (ethylene glycol)-b-polycaprolactone (mPEG-PCL), Doxorubicin (DOX), Docetaxel (DTX), paclitaxel (PTX), poly(lactic-co-glycolic acid) (PLGA), poly(lactic acid) (PLA), and Morin Hydrate (MH).

$2.5 \mu \mathrm{g} / \mathrm{mL}$. Among the nanoparticles synthesized, those with chain length PEG 1000 resulted in the best therapeutic effects. Compared to the formulations with chain lengths 2000, 3350, and 5000 , the $\mathrm{IC}_{50}$ values of the 1000 -chain polymer were $68.1 \%, 90 \%$, and $92.6 \%$ lower, respectively [119]. TPGS-coated liposomes enhanced cellular uptake and cytotoxicity of DTX in brain cancer cells [120], while targeted delivery of DTX by transferrin-conjugated TPGS micelles led to significantly higher cellular uptake and higher cytotoxicity against MDAMB-231 cells in vitro and reduced tumor size in xenograft SCID mice [121]. Based on the $\mathrm{IC}_{50}$ values, the nontargeted and targeted micelles could be 15.31- and 71.73-fold more 
effective than DTX after $24 \mathrm{~h}$ treatment. Furthermore, a TPGS-Cisplatin micellar formulation not only showed significant enhancement of Cisplatin cytotoxicity in HepG2 hepatocarcinoma cells but also showed important neuroprotective effects [122]. SH-SY5Y neuroblast-like cells, a common model for neurotoxicity test, were not greatly affected by treatment with the TPGS-Cisplatin micelle in contrast to Cisplatin alone. Therefore, it was suggested that TPGS supplementation should be adopted in patients receiving Cisplatin-based chemotherapy to reduce the neurotoxicity. In an effort to reduce the negative side effects of PTX, TPGS was used as an emulsifier in Cremophor EL-free PTX-loaded poly(lactic-coglycolic acid)- (PLGA-) mPEG nanoparticles (NP-PTX). This novel NP-PTX formulation consisting of $160.1 \mathrm{mg}$ PLGAmPEG, $40.2 \mathrm{mg}$ PTX, and 0.035\% TPGS displayed similar potency as free PTX in ovarian cancer both in vivo and in vitro and 10-fold less toxicity with no organ damage (NP-PTX $\mathrm{LD}_{50} 246.85 \mathrm{mg} / \mathrm{kg}$, free PTX $\mathrm{LD}_{50} 23.58 \mathrm{mg} / \mathrm{kg}$ ) [123]. The efficacy of PTX encapsulated in TPGS-emulsified polymeric nanoparticles (TENPs) was also examined in A549 lung cancer cells at a concentration ranging from 0.01 to $50 \mathrm{mM}$. TPGS was used as an emulsifier to facilitate nanoparticle formation in an ethanol-water system at a concentration of $0.6 \%$. The PTX-TENPs preferentially accumulated in tumors of A549 lung cancer xenograft models and significantly inhibited tumor growth following intravenous injection [124].

As previously mentioned, due to its physicochemical properties, TPGS has emerged as an ideal platform for the enhanced delivery of poorly soluble drugs. PTX and DTX are commonly used in several types of cancer and display high efficacy but they are highly lipophilic. To enhance their solubility, PTX and DTX were encapsulated in a mixed dendrimer-TPGS formulation. Dendrimers are nanomaterials that carry the guest molecule either by attachment to its surface or by encapsulation in the interior void spaces. Cells were incubated with the different concentrations (2.5-500 nM) of dendrimer-drug formulations along with free PTX and DTX for $48 \mathrm{~h}$. The solubility and anticancer activities of both compounds were greatly enhanced after encapsulation in micelles against MCF-7 and A549 cancer cells and caused very low toxicity to $\mathrm{CHO}$ normal ovarian cells [125]. TPGS-poly(lactic acid) (TPGS-PLA) micelles have been used for the simultaneous delivery of a novel triple drug combination, antitumor drugs, Crizotinib and Palbociclib, combined with Sildenafil, an agent that increases drug accumulation in the intracellular compartment. TPGSPLA copolymers encapsulated the three drugs with high loading efficiency and exhibited an improved cytotoxic effect in comparison with single (Crizotinib) or dual (CrizotinibPalbociclib) formulations in A549 lung cancer cells [126].

A TPGS derivative with a PEG 2000 chain (TPGS-2k) was found to act synergistically with DTX to reduce the viability of MCF-7 cells [127]. TPGS-2k has also been used for the stabilization of a Doxorubicin- $\alpha$-TOS conjugate. $\alpha$ TOS was connected to Doxorubicin through an amide bond to form N-Doxorubicin- $\alpha$-D-tocopherol succinate (N-DOXTOS). In aqueous solutions in the presence of TPGS-2k, this formulation self-assembled into $250 \mathrm{~nm}$ nanostructures and localized to the core of the nanoparticle. The N-DOX-TOS nanoparticles significantly reduced the growth of MCF-7 cells and induced a higher delay in tumor growth in CT26-tumorbearing mice compared to the control group [128]. In support of the specific anticancer properties of TPGS, a recent study revealed that blank TPGS nanoparticles showed toxicity against A549 lung cancer cells without harming normal cells [129]. In a nanoparticle formulation, TPGS further enhanced the toxicity of Morin Hydrate $(\mathrm{MH})$, a naturally occurring bioflavonoid, against A549 cells both in vitro and in vivo [129].

\section{Conclusions}

In conclusion, recent studies have highlighted Vitamin E isoforms and especially TPGS as ideal molecular biomaterials in developing various drug delivery systems, including micelles, nanoparticles, and liposomes. DDS serve to improve the delivery of Vitamin E isoforms so they can act as single agents against tumor cells or can be used as a platform for the combined treatment of Vitamin $E$ with chemotherapeutic drugs. Vitamin E-combined therapy represents an intriguing therapeutic strategy for common chemotherapeutics, providing not only superior efficacy but also higher safety levels. TPGS has a multifunctional nature; it can act as an anticancer agent specifically against malignant cells but may also be used in nanomedicine formulations in order to increase the bioavailability and limit of the toxicity of other agents. Based on its mechanism of action, TPGS-based DDS can be formulated to combine the effect of compounds with different activity in order to achieve simultaneous targeting of parallel pathways or sequential steps in the same pathway in cancer cells and provide additive or synergistic effects. For example, the ability of TPGS to induce apoptosis in triple negative breast cancer cells (TNBC) via the PI3K/AKT pathway [107] may serve as the basis for the development of a TPGSbased nanoparticle loaded with pharmacological inhibitors of PI3K or AKT; studies show that PI3K inhibition impairs BRCA1/2 expression and sensitizes cells to PARP inhibition in TNBC [130]. Therefore, for a synthetic lethality effect, this nanoparticle may be loaded with a specific PARP inhibitor that has also been found to be highly effective in TNBC cells. Further characterization of Vitamin E isoforms' properties and mechanisms of action will provide a new insight into the design of novel Vitamin E-based chemotherapeutics and allow the development of a series of cancer-cell-selective therapies.

\section{Conflict of Interests}

The authors declare that there is no conflict of interests regarding the publication of this paper.

\section{References}

[1] M. G. Traber and J. Atkinson, "Vitamin E, antioxidant and nothing more," Free Radical Biology and Medicine, vol. 43, no. 1, pp. 4-15, 2007.

[2] Q. Jiang, "Natural forms of vitamin E: metabolism, antioxidant, and anti-inflammatory activities and their role in disease 
prevention and therapy," Free Radical Biology \& Medicine, vol. 72, pp. 76-90, 2014.

[3] S. Khanna, S. Roy, A. Slivka et al., "Neuroprotective properties of the natural vitamin E $\alpha$-tocotrienol," Stroke, vol. 36 , no. 10, pp. 2258-2264, 2005.

[4] C. Constantinou, A. Papas, and A. I. Constantinou, "Vitamin E and cancer: an insight into the anticancer activities of vitamin $\mathrm{E}$ isomers and analogs," International Journal of Cancer, vol. 123, no. 4, pp. 739-752, 2008.

[5] B. S. Abuasal, H. Qosa, P. W. Sylvester, and A. Kaddoumi, "Comparison of the intestinal absorption and bioavailability of gamma-tocotrienol and alpha-tocopherol: in vitro, in situ and in vivo studies," Biopharmaceutics and Drug Disposition, vol. 33, no. 5, pp. 246-256, 2012.

[6] S. P. Yap, K. H. Yuen, and A. B. Lim, "Influence of route of administration on the absorption and disposition of $\alpha$-, $\gamma$ - and $\delta$-tocotrienols in rats," Journal of Pharmacy and Pharmacology, vol. 55, no. 1, pp. 53-58, 2003.

[7] B. Abuasal, P. W. Sylvester, and A. Kaddoumi, "Intestinal absorption of $\gamma$-Tocotrienol is mediated by Niemann-Pick C1like 1: in situ rat intestinal perfusion studies," Drug Metabolism and Disposition, vol. 38, no. 6, pp. 939-945, 2010.

[8] S. Alqahtani, A. Alayoubi, S. Nazzal, P. W. Sylvester, and A. Kaddoumi, "Nonlinear absorption kinetics of self-emulsifying drug delivery systems (SEDDS) containing tocotrienols as lipophilic molecules: in vivo and in vitro studies," AAPS Journal, vol. 15, no. 3, pp. 684-695, 2013.

[9] A. Kamal-Eldin and L.-Å. Appelqvist, "The chemistry and antioxidant properties of tocopherols and tocotrienols," Lipids, vol. 31, no. 7, pp. 671-701, 1996.

[10] X.-F. Wang, L. Dong, Y. Zhao, M. Tomasetti, K. Wu, and J. Neuzil, "Vitamin E analogues as anticancer agents: lessons from studies with $\alpha$-tocopheryl succinate," Molecular Nutrition \& Food Research, vol. 50, no. 8, pp. 675-685, 2006.

[11] J. Neuzil, "Vitamin E succinate and cancer treatment: a vitamin E prototype for selective antitumour activity," British Journal of Cancer, vol. 89, no. 10, pp. 1822-1826, 2003.

[12] M. G. Traber, T. Olivecrona, and H. J. Kayden, "Bovine milk lipoprotein lipase transfers tocopherol to human fibroblasts during triglyceride hydrolysis in vitro," Journal of Clinical Investigation, vol. 75, no. 5, pp. 1729-1734, 1985.

[13] M. G. Traber, G. W. Burton, L. Hughes et al., "Discrimination between forms of vitamin $\mathrm{E}$ by humans with and without genetic abnormalities of lipoprotein metabolism," The Journal of Lipid Research, vol. 33, no. 8, pp. 1171-1182, 1992.

[14] J. K. Lodge, J. Ridlington, S. Leonard, H. Vaule, and M. G. Traber, "Alpha- and gamma-tocotrienols are metabolized to carboxyethyl-hydroxychroman derivatives and excreted in human urine," Lipids, vol. 36, no. 1, pp. 43-48, 2001.

[15] S. Fairus, R. M. Nor, H. M. Cheng, and K. Sundram, "Postprandial metabolic fate of tocotrienol-rich vitamin $\mathrm{E}$ differs significantly from that of $\alpha$-tocopherol," American Journal of Clinical Nutrition, vol. 84, no. 4, pp. 835-842, 2006.

[16] S. P. Yap, K. H. Yuen, and J. W. Wong, "Pharmacokinetics and bioavailability of $\alpha$-, $\gamma$ - and $\delta$-tocotrienols under different food status," Journal of Pharmacy and Pharmacology, vol. 53, no. 1, pp. 67-71, 2001.

[17] I. Ikeda, Y. Imasato, E. Sasaki, and M. Sugano, "Lymphatic transport of $\alpha$-, $\gamma$-, and $\delta$-tocotrienols and $\alpha$-tocopherol in rats," International Journal for Vitamin and Nutrition Research, vol. 66, no. 3, pp. 217-221, 1996.
[18] S. Khanna, V. Patel, C. Rink, S. Roy, and C. K. Sen, "Delivery of orally supplemented $\alpha$-tocotrienol to vital organs of rats and tocopherol-transport protein deficient mice," Free Radical Biology and Medicine, vol. 39, no. 10, pp. 1310-1319, 2005.

[19] V. A. Tiurin, V. E. Kagan, N. F. Avrova, and M. P. Prozorovskaia, "Lipid asymmetry and alpha-tocopherol distribution in outer and inner monolayers of bilayer lipid membranes," Bulletin of Experimental Biology and Medicine, vol. 105, pp. 667-669, 1988.

[20] V. A. Tyurin, V. E. Kagan, E. A. Serbinova, N. V. Gorbunov, and A. N. Erin, "The interaction of alpha-tocopherol with phospholipid liposomes: the absence of transbilayer mobility," Biulleten' Eksperimental'noĭ Biologii i Meditsiny, vol. 102, no. 12, pp. 689-692, 1986.

[21] P. Mardones and A. Rigotti, "Cellular mechanisms of vitamin e uptake: relevance in alpha-tocopherol metabolism and potential implications for disease," Journal of Nutritional Biochemistry, vol. 15, no. 5, pp. 252-260, 2004.

[22] M. G. Traber and H. J. Kayden, "Vitamin E is delivered to cells via the high affinity receptor for low-density lipoprotein," The American Journal of Clinical Nutrition, vol. 40, no. 4, pp. 747751, 1984.

[23] C. A. Thellman and R. B. Shireman, "In vitro uptake of $[3 \mathrm{H}] \alpha-$ tocopherol from low density lipoprotein by cultured human fibroblasts," Journal of Nutrition, vol. 115, no. 12, pp. 1673-1679, 1985.

[24] I. Kolleck, H. Wissel, F. Guthmann, M. Schlame, P. Sinha, and B. Rüstow, "HDL-holoparticle uptake by alveolar type II cells: effect of vitamin E status," The American Journal of Respiratory Cell and Molecular Biology, vol. 27, no. 1, pp. 57-63, 2002.

[25] D. Goti, A. Hrzenjak, S. Levak-Frank et al., "Scavenger receptor class B, type I is expressed in porcine brain capillary endothelial cells and contributes to selective uptake of HDL-associated vitamin E," Journal of Neurochemistry, vol. 76, no. 2, pp. 498508, 2001.

[26] I. Kolleck, M. Schlame, H. Fechner, A. C. Looman, H. Wissel, and B. Rüstow, "HDL is the major source of vitamin E for type II pneumocytes," Free Radical Biology and Medicine, vol. 27, no. 7-8, pp. 882-890, 1999.

[27] P. Mardones, P. Strobel, S. Miranda et al., "Alpha-tocopherol metabolism is abnormal in scavenger receptor class B type I (SRBI)-deficient mice," Journal of Nutrition, vol. 132, no. 3, pp. 443449, 2002.

[28] W. Witt, I. Kolleck, H. Fechner, P. Sinha, and B. Rüstow, "Regulation by vitamin $\mathrm{E}$ of the scavenger receptor BI in rat liver and HepG2 cells," Journal of Lipid Research, vol. 41, no. 12, pp. 2009-2016, 2000.

[29] J. Qian, S. Morley, K. Wilson, P. Nava, J. Atkinson, and D. Manor, "Intracellular trafficking of vitamin E in hepatocytes: the role of tocopherol transfer protein," The Journal of Lipid Research, vol. 46, no. 10, pp. 2072-2082, 2005.

[30] M. Horiguchi, M. Arita, D. E. Kaempf-Rotzoll, M. Tsujimoto, K. Inoue, and H. Arai, "pH-dependent translocation of $\alpha$ tocopherol transfer protein $(\alpha$-TTP) between hepatic cytosol and late endosomes," Genes to Cells, vol. 8, no. 10, pp. 789-800, 2003.

[31] N. Kaplowitz, H. Yoshida, J. Kuhlenkamp, B. Slitsky, I. Ren, and A. Stolz, "Tocopherol-binding proteins of hepatic cytosol," Annals of the New York Academy of Sciences, vol. 570, pp. 85-94, 1989.

[32] J. B. Massey, "Kinetics of transfer of $\alpha$-tocopherol between model and native plasma lipoproteins," Biochimica et Biophysica Acta, vol. 793, no. 3, pp. 387-392, 1984. 
[33] J. Qian, K. Wilson, P. Nava, S. Morley, J. Atkinson, and D. Manor, "Intracellular localization of $\alpha$-tocopherol transfer protein and $\alpha$-tocopherol," Annals of the New York Academy of Sciences, vol. 1031, pp. 330-331, 2004.

[34] L. Ulatowski, R. Parker, C. Davidson et al., "Altered vitamin E status in Niemann-Pick type C disease," Journal of Lipid Research, vol. 52, no. 7, pp. 1400-1410, 2011.

[35] L. F. Yévenes, A. Klein, J. F. Castro et al., "Lysosomal vitamin E accumulation in Niemann-Pick type C disease," Biochimica et Biophysica Acta, vol. 1822, no. 2, pp. 150-160, 2012.

[36] C. A. Drevon, "Absorption, transport and metabolism of vitamin E," Free Radical Research Communications, vol. 14, no. 4, pp. 229-246, 1991.

[37] J.-M. Zingg and A. Azzi, "Non-antioxidant activities of vitamin E," Current Medicinal Chemistry, vol. 11, no. 9, pp. 1113-1133, 2004.

[38] K. Hensley, E. J. Benaksas, R. Bolli et al., "New perspectives on vitamin E: $\gamma$-tocopherol and carboxyethylhydroxychroman metabolites in biology and medicine," Free Radical Biology and Medicine, vol. 36, no. 1, pp. 1-15, 2004.

[39] F. Berrino and P. Muti, "Mediterranean diet and cancer," European Journal of Clinical Nutrition, vol. 43, supplement 2, pp. 49-55, 1989.

[40] M. Khlat, "Cancer in Mediterranean migrants-based on studies in France and Australia," Cancer Causes and Control, vol. 6, no. 6, pp. 525-531, 1995.

[41] O. P. Heinonen, D. Albanes, J. Virtamo et al., "Prostate cancer and supplementation with $\alpha$-tocopherol and $\beta$-carotene: incidence and mortality in a controlled trial," Journal of the National Cancer Institute, vol. 90, no. 6, pp. 440-446, 1998.

[42] M. E. Wright, S. J. Weinstein, K. A. Lawson et al., "Supplemental and dietary vitamin $\mathrm{E}$ intakes and risk of prostate cancer in a large prospective study," Cancer Epidemiology Biomarkers and Prevention, vol. 16, no. 6, pp. 1128-1135, 2007.

[43] H. L. Parnes, M. G. House, J. Kagan et al., "Prostate cancer chemoprevention agent development: the National Cancer Institute, Division of Cancer Prevention portfolio," Journal of Urology, vol. 171, no. 2, pp. S68-S75, 2004.

[44] T. Weber, M. Lu, L. Andera et al., "Vitamin E succinate is a potent novel antineoplastic agent with high selectivity and cooperativity with tumor necrosis factor-related apoptosisinducing ligand (Apo2 ligand) in vivo," Clinical Cancer Research, vol. 8, no. 3, pp. 863-869, 2002.

[45] H. Ahsan, A. Ahad, J. Iqbal, and W. A. Siddiqui, "Pharmacological potential of tocotrienols: a review," Nutrition \& Metabolism, vol. 11, no. 1, article 52, 2014.

[46] S. J. Shah and P. W. Sylvester, " $\gamma$-tocotrienol inhibits neoplastic mammary epithelial cell proliferation by decreasing Akt and nuclear factor $\kappa \mathrm{B}$ activity," Experimental Biology and Medicine, vol. 230, no. 4, pp. 235-241, 2005.

[47] K. S. Ahn, G. Sethi, K. Krishnan, and B. B. Aggarwal, "Gammatocotrienol inhibits nuclear factor-kappaB signaling pathway through inhibition of receptor-interacting protein and TAK1 leading to suppression of antiapoptotic gene products and potentiation of apoptosis," The Journal of Biological Chemistry, vol. 282, no. 1, pp. 809-820, 2007.

[48] M. Sakai, M. Okabe, H. Tachibana, and K. Yamada, "Apoptosis induction by $\gamma$-tocotrienol in human hepatoma Hep3B cells," Journal of Nutritional Biochemistry, vol. 17, no. 10, pp. 672-676, 2006.
[49] Y. Li, T. Hahn, K. Garrison et al., "The vitamin E analogue $\alpha$ TEA stimulates tumor autophagy and enhances antigen crosspresentation," Cancer Research, vol. 72, no. 14, pp. 3535-3545, 2012.

[50] R. Tiwary, W. Yu, B. G. Sanders, and K. Kline, " $\alpha$-TEA cooperates with chemotherapeutic agents to induce apoptosis of p53 mutant, triple-negative human breast cancer cells via activating p73," Breast Cancer Research, vol. 13, no. 1, article R1, 2011.

[51] R. Tiwary, W. Yu, B. G. Sanders, and K. Kline, " $\alpha$-TEA cooperates with MEK or mTOR inhibitors to induce apoptosis via targeting IRS/PI3K pathways," British Journal of Cancer, vol. 104, no. 1, pp. 101-109, 2011.

[52] K. Anderson, M. Simmons-Menchaca, K. A. Lawson, J. Atkinson, B. G. Sanders, and K. Kline, "Differential response of human ovarian cancer cells to induction of apoptosis by vitamin E succinate and vitamin E analogue, $\alpha$-TEA," Cancer Research, vol. 64, no. 12, pp. 4263-4269, 2004.

[53] K. A. Lawson, K. Anderson, M. Menchaca et al., "Novel vitamin $\mathrm{E}$ analogue decreases syngeneic mouse mammary tumor burden and reduces lung metastasis," Molecular Cancer Therapeutics, vol. 2, no. 5, pp. 437-444, 2003.

[54] J. Neuzil, L.-F. Dong, J. Rohlena, J. Truksa, and S. J. Ralph, "Classification of mitocans, anti-cancer drugs acting on mitochondria," Mitochondrion, vol. 13, no. 3, pp. 199-208, 2013.

[55] J. Neuzil, T. Weber, A. Schröder et al., "Induction of cancer cell apoptosis by $\alpha$-tocopheryl succinate: molecular pathways and structural requirements," The FASEB Journal, vol. 15, no. 2, pp. 403-415, 2001.

[56] R. Tiwary, W. Yu, J. Li, S.-K. Park, B. G. Sanders, and K. Kline, "Role of endoplasmic reticulum stress in $\alpha$-tea mediated TRAIL/DR5 death receptor dependent apoptosis," PLoS ONE, vol. 5, no. 7, Article ID el1865, 2010.

[57] C. Wadsack, A. Hrzenjak, A. Hammer et al., “Trophoblastlike human choriocarcinoma cells serve as a suitable in vitro model for selective cholesteryl ester uptake from high density lipoproteins," European Journal of Biochemistry, vol. 270, no. 3, pp. 451-462, 2003.

[58] C. Wadsack, B. Hirschmugl, A. Hammer et al., "Scavenger receptor class $B$, type I on non-malignant and malignant human epithelial cells mediates cholesteryl ester-uptake from high density lipoproteins," The International Journal of Biochemistry \& Cell Biology, vol. 35, no. 4, pp. 441-454, 2003.

[59] A. Hrzenjak, H. Reicher, A. Wintersperger et al., "Inhibition of lung carcinoma cell growth by high density lipoproteinassociated $\alpha$-tocopheryl-succinate," Cellular and Molecular Life Sciences, vol. 61, no. 12, pp. 1520-1531, 2004.

[60] J. Neuzil, L.-F. Dong, L. Ramanathapuram et al., "Vitamin E analogues as a novel group of mitocans: anti-cancer agents that act by targeting mitochondria," Molecular Aspects of Medicine, vol. 28, no. 5-6, pp. 607-645, 2007.

[61] L. F. Dong, V. J. Jameson, D. Tilly et al., "Mitochondrial targeting of alpha-tocopheryl succinate enhances its pro-apoptotic efficacy: a new paradigm for effective cancer therapy," Free Radical Biology \& Medicine, vol. 50, pp. 1546-1555, 2011.

[62] R. A. J. Smith, C. M. Porteous, A. M. Gane, and M. P. Murphy, "Delivery of bioactive molecules to mitochondria in vivo," Proceedings of the National Academy of Sciences of the United States of America, vol. 100, no. 9, pp. 5407-5412, 2003. 
[63] J. Kovarova, M. Bajzikova, M. Vondrusova et al., "Mitochondrial targeting of $\alpha$-tocopheryl succinate enhances its antimesothelioma efficacy," Redox Report, vol. 19, no. 1, pp. 16-25, 2014.

[64] J. Truksa, L. F. Dong, J. Rohlena et al., "Mitochondrially targeted vitamin e succinate modulates expression of mitochondrial DNA transcripts and mitochondrial biogenesis," Antioxidants \& Redox Signaling, vol. 22, no. 11, pp. 883-900, 2015.

[65] S. Hama, S. Utsumi, Y. Fukuda et al., "Development of a novel drug delivery system consisting of an antitumor agent tocopheryl succinate," Journal of Controlled Release, vol. 161, no. 3, pp. 843-851, 2012.

[66] Y. Matsumura and H. Maeda, "A new concept for macromolecular therapeutics in cancer chemotherapy: mechanism of tumoritropic accumulation of proteins and the antitumor agent smancs," Cancer Research, vol. 46, no. 12 I, pp. 6387-6392, 1986.

[67] K. Greish, "Enhanced permeability and retention (EPR) effect for anticancer nanomedicine drug targeting," Methods in Molecular Biology, vol. 624, pp. 25-37, 2010.

[68] A. Tomic-Vatic, J. Eytina, J. Chapman, E. Mahdavian, J. Neuzil, and B. A. Salvatore, "Vitamin E amides, a new class of vitamin $\mathrm{E}$ analogues with enhanced proapoptotic activity," International Journal of Cancer, vol. 117, no. 2, pp. 188-193, 2005.

[69] J. Turánek, X.-F. Wang, P. Knötigová et al., "Liposomal formulation of $\alpha$-tocopheryl maleamide: in vitro and in vivo toxicological profile and anticancer effect against spontaneous breast carcinomas in mice," Toxicology and Applied Pharmacology, vol. 237, no. 3, pp. 249-257, 2009.

[70] K. A. Lawson, K. Anderson, R. M. Snyder et al., "Novel vitamin $\mathrm{E}$ analogue and 9-nitro-camptothecin administered as liposome aerosols decrease syngeneic mouse mammary tumor burden and inhibit metastasis," Cancer Chemotherapy and Pharmacology, vol. 54, no. 5, pp. 421-431, 2004.

[71] H. Montazeri Aliabadi, D. R. Brocks, and A. Lavasanifar, "Polymeric micelles for the solubilization and delivery of cyclosporine A: pharmacokinetics and biodistribution," Biomaterials, vol. 26, no. 35, pp. 7251-7259, 2005.

[72] V. P. Torchilin, "Micellar nanocarriers: pharmaceutical perspectives," Pharmaceutical Research, vol. 24, no. 1, pp. 1-16, 2007.

[73] H. Maeda, J. Wu, T. Sawa, Y. Matsumura, and K. Hori, “Tumor vascular permeability and the EPR effect in macromolecular therapeutics: a review," Journal of Controlled Release, vol. 65, no. 1-2, pp. 271-284, 2000.

[74] N. Liang, S. Sun, X. Li, H. Piao, F. Cui, and L. Fang, "Alphatocopherol succinate-modified chitosan as a micellar delivery system for paclitaxel: preparation, characterization and in vitro/in vivo evaluations," International Journal of Pharmaceutics, vol. 423, no. 2, pp. 480-488, 2012.

[75] J. Emami, M. Rezazadeh, M. Rostami et al., "Co-delivery of paclitaxel and $\alpha$-tocopherol succinate by novel chitosan-based polymeric micelles for improving micellar stability and efficacious combination therapy," Drug Development and Industrial Pharmacy, pp. 1-11, 2014.

[76] H. Akita, R. Ishiba, H. Hatakeyama et al., "A neutral envelopetype nanoparticle containing $\mathrm{pH}$-responsive and SS-cleavable lipid-like material as a carrier for plasmid DNA," Advanced Healthcare Materials, vol. 2, no. 8, pp. 1120-1125, 2013.

[77] H. Akita, R. Ishiba, R. Togashi et al., "A neutral lipid envelopetype nanoparticle composed of a $\mathrm{pH}$-activated and vitamin E-scaffold lipid-like material as a platform for a gene carrier targeting renal cell carcinoma," Journal of Controlled Release, vol. 200, pp. 97-105, 2015.
[78] J. Y. Fu, D. R. Blatchford, L. Tetley, and C. Dufès, “Tumor regression after systemic administration of tocotrienol entrapped in tumor-targeted vesicles," Journal of Controlled Release, vol. 140, no. 2, pp. 95-99, 2009.

[79] J. Y. Fu, W. Zhang, D. R. Blatchford, L. Tetley, G. McConnell, and C. Dufès, "Novel tocotrienol-entrapping vesicles can eradicate solid tumors after intravenous administration," Journal of Controlled Release, vol. 154, no. 1, pp. 20-26, 2011.

[80] A. B. Shirode and P. W. Sylvester, "Synergistic anticancer effects of combined $\gamma$-tocotrienol and celecoxib treatment are associated with suppression in Akt and $\mathrm{NF} \kappa \mathrm{B}$ signaling," Biomedicine and Pharmacotherapy, vol. 64, no. 5, pp. 327-332, 2010.

[81] S. V. Bachawal, V. B. Wali, and P. W. Sylvester, "Combined $\gamma$-tocotrienol and erlotinib/gefitinib treatment suppresses Stat and Akt signaling in murine mammary tumor cells," Anticancer Research, vol. 30, no. 2, pp. 429-437, 2010.

[82] V. B. Wali and P. W. Sylvester, "Synergistic antiproliferative effects of $\gamma$-tocotrienol and statin treatment on mammary tumor cells," Lipids, vol. 42, no. 12, pp. 1113-1123, 2007.

[83] M. M. Fryd and T. G. Mason, "Advanced nanoemulsions," Annual Review of Physical Chemistry, vol. 63, pp. 493-518, 2012.

[84] A. Y. Alayoubi, J. F. Anderson, S. D. Satyanarayanajois, P. W. Sylvester, and S. Nazzal, "Concurrent delivery of tocotrienols and simvastatin by lipid nanoemulsions potentiates their antitumor activity against human mammary adenocarcenoma cells," European Journal of Pharmaceutical Sciences, vol. 48, no. 3, pp. 385-392, 2013.

[85] J. Pham, A. Nayel, C. Hoang, and T. Elbayoumi, "Enhanced effectiveness of tocotrienol-based nano-emulsified system for topical delivery against skin carcinomas," Drug Delivery, pp. 111, 2014.

[86] M. Nasr, N. Nafee, H. Saad, and A. Kazem, "Improved antitumor activity and reduced cardiotoxicity of epirubicin using hepatocyte-targeted nanoparticles combined with tocotrienols against hepatocellular carcinoma in mice," European Journal of Pharmaceutics and Biopharmaceutics, vol. 88, no. 1, pp. 216-225, 2014.

[87] Z. Zhang, S. Tan, and S. S. Feng, "Vitamin E TPGS as a molecular biomaterial for drug delivery," Biomaterials, vol. 33, pp. 4889-4906, 2012.

[88] Y. Guo, J. Luo, S. Tan, B. O. Otieno, and Z. Zhang, "The applications of Vitamin e TPGS in drug delivery," European Journal of Pharmaceutical Sciences, vol. 49, no. 2, pp. 175-186, 2013.

[89] M. G. Traber, T. D. Schiano, A. C. Steephen, H. J. Kayden, and M. Shike, "Efficacy of water-soluble vitamin E in the treatment of vitamin E malabsorption in short-bowel syndrome," The American Journal of Clinical Nutrition, vol. 59, no. 6, pp. 12701274, 1994.

[90] R. J. Sokol, N. Butler-Simon, C. Conner et al., "Multicenter trial of d- $\alpha$-tocopheryl polyethylene glycol 1000 succinate for treatment of vitamin E deficiency in children with chronic cholestasis," Gastroenterology, vol. 104, no. 6, pp. 1727-1735, 1993.

[91] R. J. Sokol, N. A. Butler-Simon, D. Bettis, D. J. Smith, and A. Silverman, "Tocopheryl polyethylene glycol 1000 succinate therapy for vitamin E deficiency during chronic childhood cholestasis: neurologic outcome," The Journal of Pediatrics, vol. 111, no. 6, pp. 830-836, 1987.

[92] P. P. Constantinides, J. Han, and S. S. Davis, "Advances in the use of tocols as drug delivery vehicles," Pharmaceutical Research, vol. 23, no. 2, pp. 243-255, 2006. 
[93] M. V. S. Varma and R. Panchagnula, "Enhanced oral paclitaxel absorption with vitamin E-TPGS: effect on solubility and permeability in vitro, in situ and in vivo," European Journal of Pharmaceutical Sciences, vol. 25, no. 4-5, pp. 445-453, 2005.

[94] W. J. Krasavage and C. J. Terhaar, "d- $\alpha$-tocopheryl poly(ethylene glycol) 1000 succinate: acute toxicity, subchronic feeding, reproduction, and teratologic studies in the rat," Journal of Agricultural and Food Chemistry, vol. 25, no. 2, pp. 273-278, 1977.

[95] EFSA Panel on Food Additives- Flavourings- Processing Aids and Materials in Contact with Food (AFC), "Opinion of the Scientific Panel on food additives, flavourings, processing aids and materials in contact with food (AFC) related to D-alphatocopheryl polyethylene glycol 1000 succinate (TPGS) in use for food for particular nutritional purposes," EFSA Journal, 2007, http://www.efsa.europa.eu/en/efsajournal/pub/490.htm.

[96] M. G. Traber, C. A. Thellman, M. J. Rindler, and H. J. Kayden, "Uptake of intact TPGS (d- $\alpha$-tocopheryl polyethylene glycol 1000 succinate) a water-miscible form of vitamin E by human cells in vitro," The American Journal of Clinical Nutrition, vol. 48, no. 3, pp. 605-611, 1988.

[97] L. Mu and S. S. Feng, "Vitamin E TPGS used as emulsifier in the solvent evaporation/extraction technique for fabrication of polymeric nanospheres for controlled release of paclitaxel (Taxol)," Journal of Controlled Release, vol. 80, no. 1-3, pp. 129144, 2002.

[98] J. Pan, Y. Wang, and S.-S. Feng, "Formulation, characterization, and in vitro evaluation of quantum dots loaded in poly(Lactide)-Vitamin E TPGS nanoparticles for cellular and molecular imaging," Biotechnology and Bioengineering, vol. 101, no. 3, pp. 622-633, 2008.

[99] J. M. Dintaman and J. A. Silverman, "Inhibition of Pglycoprotein by D- $\alpha$-tocopheryl polyethylene glycol 1000 succinate (TPGS)," Pharmaceutical Research, vol. 16, no. 10, pp. 15501556, 1999.

[100] L. Mu, T. A. Elbayoumi, and V. P. Torchilin, "Mixed micelles made of poly(ethylene glycol)-phosphatidylethanolamine conjugate and D- $\alpha$-tocopheryl polyethylene glycol 1000 succinate as pharmaceutical nanocarriers for camptothecin," International Journal of Pharmaceutics, vol. 306, no. 1-2, pp. 142-149, 2005.

[101] S.-S. Feng, "New-concept chemotherapy by nanoparticles of biodegradable polymers: where are we now?" Nanomedicine, vol. 1, no. 3, pp. 297-309, 2006.

[102] K. Y. Win and S.-S. Feng, "In vitro and in vivo studies on vitamin E TPGS-emulsified poly(D,L-lactic-co-glycolic acid) nanoparticles for paclitaxel formulation," Biomaterials, vol. 27, no. 10, pp. 2285-2291, 2006.

[103] P. Parhi, C. Mohanty, and S. K. Sahoo, "Enhanced cellular uptake and in vivo pharmacokinetics of rapamycin-loaded cubic phase nanoparticles for cancer therapy," Acta Biomaterialia, vol. 7, no. 10, pp. 3656-3669, 2011.

[104] C. S. Muenyi, Cell Toxicology Study of RRR-Alpha-Tocopheryl Polyethylene Glycol 1000 Succinate (TPGS), East Tennessee State University, 2005.

[105] H.-J. Youk, E. Lee, M.-K. Choi et al., "Enhanced anticancer efficacy of $\alpha$-tocopheryl succinate by conjugation with polyethylene glycol," Journal of Controlled Release, vol. 107, no. 1, pp. 4352, 2005.

[106] C. Constantinou, C. M. Neophytou, P. Vraka, J. A. Hyatt, K. A. Papas, and A. I. Constantinou, "Induction of DNA damage and caspase-independent programmed cell death by vitamin E," Nutrition and Cancer, vol. 64, no. 1, pp. 136-152, 2012.

[107] C. M. Neophytou, C. Constantinou, P. Papageorgis, and A. I. Constantinou, "D-alpha-tocopheryl polyethylene glycol succinate (TPGS) induces cell cycle arrest and apoptosis selectively in Survivin-overexpressing breast cancer cells," Biochemical Pharmacology, vol. 89, no. 1, pp. 31-42, 2014.

[108] M. di Cagno, P. C. Stein, J. Styskala, J. Hlaváč, N. SkalkoBasnet, and A. Bauer-Brandl, "Overcoming instability and low solubility of new cytostatic compounds: a comparison of two approaches," European Journal of Pharmaceutics and Biopharmaceutics, vol. 80, no. 3, pp. 657-662, 2012.

[109] L. Yu, A. Bridgers, J. Polli et al., "Vitamin E-TPGS increases absorption flux of an HIV protease inhibitor by enhancing its solubility and permeability," Pharmaceutical Research, vol. 16, no. 12, pp. 1812-1817, 1999.

[110] T. Chang, L. Z. Benet, and M. F. Hebert, "The effect of watersoluble vitamin $\mathrm{E}$ on cyclosporine pharmacokinetics in healthy volunteers," Clinical Pharmacology and Therapeutics, vol. 59, no. 3, pp. 297-303, 1996.

[111] J. Brouwers, J. Tack, F. Lammert, and P. Augustijns, "Intraluminal drug and formulation behavior and integration in in vitro permeability estimation: a case study with amprenavir," Journal of Pharmaceutical Sciences, vol. 95, no. 2, pp. 372-383, 2006.

[112] E.-M. Collnot, C. Baldes, M. F. Wempe et al., "Mechanism of inhibition of P-glycoprotein mediated efflux by vitamin $\mathrm{E}$ TPGS: influence on ATPase activity and membrane fluidity," Molecular Pharmaceutics, vol. 4, no. 3, pp. 465-474, 2007.

[113] U. Hanke, K. May, V. Rozehnal, S. Nagel, W. Siegmund, and W. Weitschies, "Commonly used nonionic surfactants interact differently with the human efflux transporters ABCB1 (p-glycoprotein) and ABCC2 (MRP2)," European Journal of Pharmaceutics and Biopharmaceutics, vol. 76, no. 2, pp. 260268, 2010.

[114] E.-M. Collnot, C. Baldes, M. F. Wempe et al., "Influence of vitamin E TPGS poly(ethylene glycol) chain length on apical efflux transporters in Caco-2 cell monolayers," Journal of Controlled Release, vol. 111, no. 1-2, pp. 35-40, 2006.

[115] A. Christiansen, T. Backensfeld, K. Denner, and W. Weitschies, "Effects of non-ionic surfactants on cytochrome P450-mediated metabolism in vitro," European Journal of Pharmaceutics and Biopharmaceutics, vol. 78, no. 1, pp. 166-172, 2011.

[116] M.-J. Shieh, C.-Y. Hsu, L.-Y. Huang, H.-Y. Chen, F.-H. Huang, and P.-S. Lai, "Reversal of doxorubicin-resistance by multifunctional nanoparticles in MCF-7/ADR cells," Journal of Controlled Release, vol. 152, no. 3, pp. 418-425, 2011.

[117] P. Yu, H. Yu, C. Guo et al., "Reversal of doxorubicin resistance in breast cancer by mitochondria-targeted $\mathrm{pH}$-responsive micelles," Acta Biomaterialia, vol. 14, pp. 115-124, 2015.

[118] S. Wang, R. Chen, J. Morott, M. A. Repka, Y. Wang, and M. Chen, "mPEG-b-PCL/TPGS mixed micelles for delivery of resveratrol in overcoming resistant breast cancer," Expert Opinion on Drug Delivery, vol. 12, no. 3, pp. 361-373, 2015.

[119] J. Zhao and S.-S. Feng, "Effects of PEG tethering chain length of vitamin E TPGS with a Herceptin-functionalized nanoparticle formulation for targeted delivery of anticancer drugs," Biomaterials, vol. 35, no. 10, pp. 3340-3347, 2014.

[120] M. S. Muthu, S. A. Kulkarni, J. Xiong, and S.-S. Feng, "Vitamin e TPGS coated liposomes enhanced cellular uptake and cytotoxicity of docetaxel in brain cancer cells," International Journal of Pharmaceutics, vol. 421, no. 2, pp. 332-340, 2011. 
[121] M. S. Muthu, R. V. Kutty, Z. Luo, J. Xie, and S. S. Feng, "Theranostic vitamin E TPGS micelles of transferrin conjugation for targeted co-delivery of docetaxel and ultra bright gold nanoclusters," Biomaterials, vol. 39, pp. 234-248, 2015.

[122] Y. Mi, J. Zhao, and S.-S. Feng, "Vitamin e TPGS prodrug micelles for hydrophilic drug delivery with neuroprotective effects," International Journal of Pharmaceutics, vol. 438, no. 1-2, pp. 98-106, 2012.

[123] W. Lv, L. Cheng, and B. Li, "Development and evaluation of a novel TPGS-mediated paclitaxel-loaded PLGA-mPEG nanoparticle for the treatment of ovarian cancer," Chemical and Pharmaceutical Bulletin, vol. 63, no. 2, pp. 68-74, 2015.

[124] Y. Sun, B. Yu, G. Wang et al., "Enhanced antitumor efficacy of vitamin E TPGS-emulsified PLGA nanoparticles for delivery of paclitaxel," Colloids and Surfaces B: Biointerfaces, vol. 123, pp. 716-723, 2014.

[125] D. Pooja, H. Kulhari, M. K. Singh, S. Mukherjee, S. S. Rachamalla, and R. Sistla, "Dendrimer-TPGS mixed micelles for enhanced solubility and cellular toxicity of taxanes," Colloids and Surfaces B: Biointerfaces, vol. 121, pp. 461-468, 2014.

[126] D. de Melo-Diogo, V. M. Gaspar, E. C. Costa et al., "Combinatorial delivery of Crizotinib-Palbociclib-Sildenafil using TPGSPLA micelles for improved cancer treatment," European Journal of Pharmaceutics and Biopharmaceutics, vol. 88, no. 3, pp. 718729, 2014.

[127] Y. Mi, Y. Liu, and S.-S. Feng, "Formulation of Docetaxel by folic acid-conjugated $\mathrm{D}$ - $\alpha$-tocopheryl polyethylene glycol succinate 2000 (Vitamin $\mathrm{E} \mathrm{TPGS}_{2 k}$ ) micelles for targeted and synergistic chemotherapy," Biomaterials, vol. 32, no. 16, pp. 4058-4066, 2011.

[128] N. Duhem, F. Danhier, V. Pourcelle et al., "Self-assembling doxorubicin-tocopherol succinate prodrug as a new drug delivery system: synthesis, characterization, and in vitro and in vivo anticancer activity," Bioconjugate Chemistry, vol. 25, no. 1, pp. 72-81, 2014.

[129] S. Abbad, C. Wang, A. Y. Waddad, H. Lv, and J. Zhou, "Preparation, in vitro and in vivo evaluation of polymeric nanoparticles based on hyaluronic acid-poly(butyl cyanoacrylate) and Dalpha-tocopheryl polyethylene glycol 1000 succinate for tumortargeted delivery of morin hydrate," International Journal of Nanomedicine, vol. 10, pp. 305-320, 2015.

[130] Y. H. Ibrahim, C. García-García, V. Serra et al., "PI3K inhibition impairs BRCA1/2 expression and sensitizes BRCA-proficient triple-negative breast cancer to PARP inhibition," Cancer Discovery, vol. 2, no. 11, pp. 1036-1047, 2012.

[131] G. Orive, E. Anitua, J. L. Pedraz, and D. F. Emerich, "Biomaterials for promoting brain protection, repair and regeneration," Nature Reviews Neuroscience, vol. 10, no. 9, pp. 682-692, 2009. 

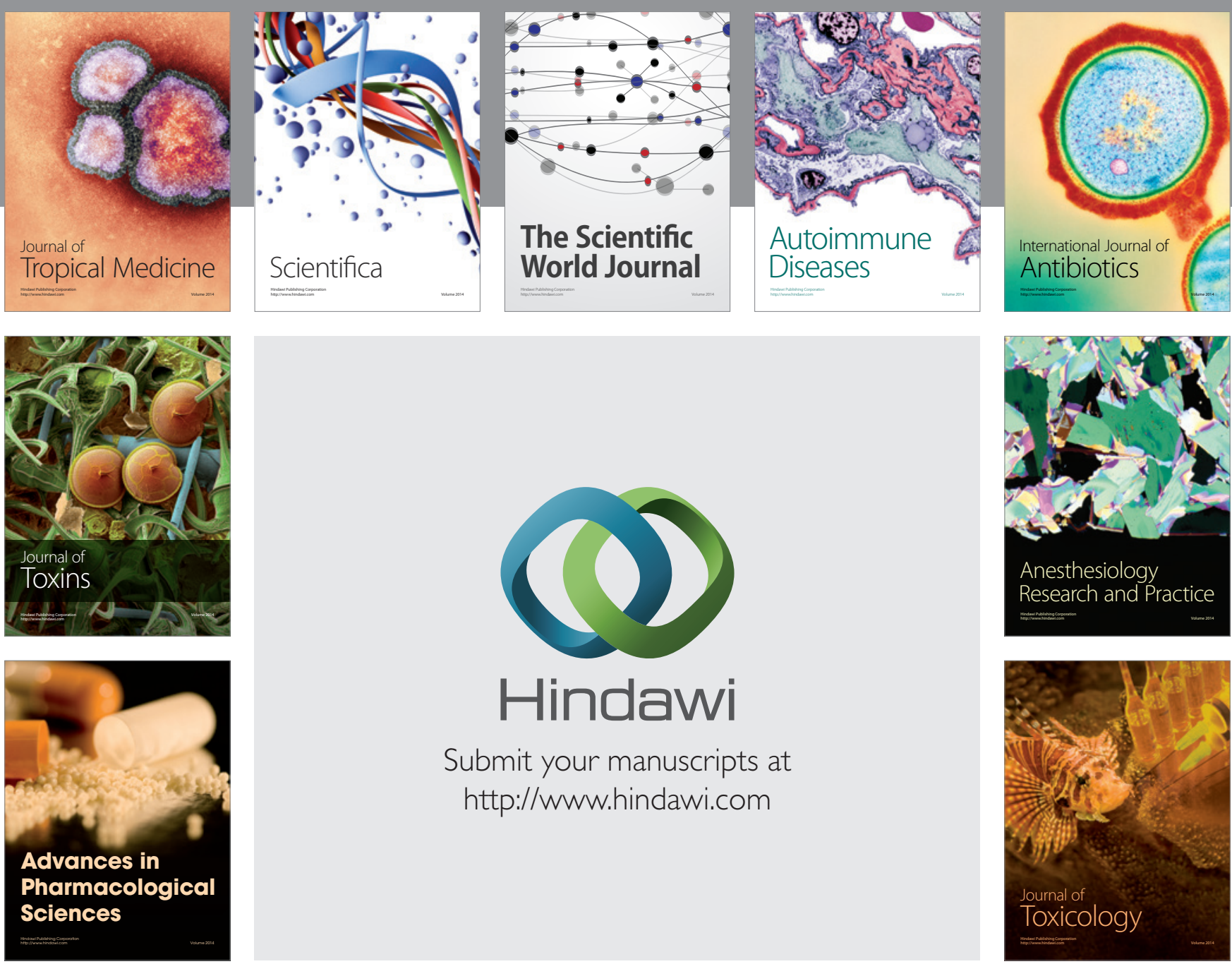

\section{Hindawi}

Submit your manuscripts at

http://www.hindawi.com
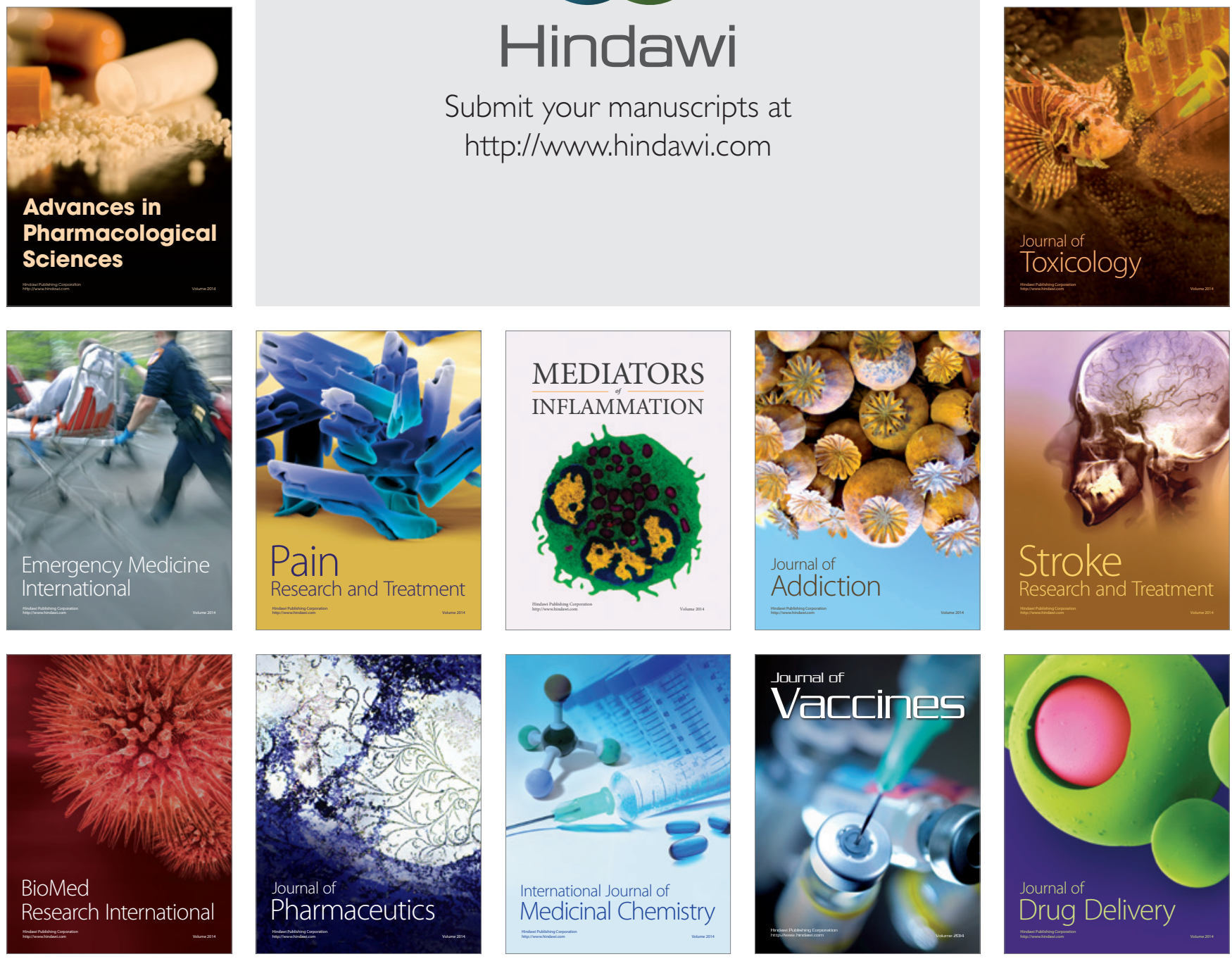